\title{
Osteology of Tucanoichthys tucano Géry and Römer, an enigmatic miniature fish from the Amazon basin, Brazil (Teleostei: Characiformes: Characidae)
}

\author{
George M.T. Mattox ${ }^{1}$ Kevin W. Conway ${ }^{2}$ \\ 1 Laboratório de Ictiologia de Sorocaba, Departamento de Biologia, Universidade Federal de São Carlos - campus Sorocaba, São Paulo, \\ 18052-780, Brazil \\ 2 Department of Ecology and Conservation Biology and Biodiversity Research and Teaching Collections, Texas A\&M University, 2258 TAMU, \\ College Station, Texas, 77843, United States \\ http://zoobank.org/39AB2912-F7A9-443F-94D5-C9228012CE32
}

Corresponding author: George M.T. Mattox (gmattox@ufscar.br)

\begin{tabular}{|c|c|c|c|}
\hline Academic editor Ralf Britz & Received 21 July 2021 & Accepted 5 October 2021 & Published 18 October 2021 \\
\hline
\end{tabular}

Citation: Mattox GMT, Conway KW (2021) Osteology of Tucanoichthys tucano Géry and Römer, an enigmatic miniature fish from the Amazon basin, Brazil (Teleostei: Characiformes: Characidae). Vertebrate Zoology 71 645-667. https://doi.org/10.3897/vz.71.e71886

\begin{abstract}
Miniaturization, the evolution of extremely small adult body size, is a common phenomenon across the lineages of freshwater fishes, especially in the Neotropics where over 200 species are considered miniature ( $\leq 26 \mathrm{~mm}$ in standard length [SL]). Close to $30 \%$ of all miniature Neotropical freshwater fishes belong to the family Characidae, several of which are of uncertain phylogenetic placement within the family. We investigate the skeletal anatomy of Tucanoichthys tucano, a species of uncertain phylogenetic position from the upper Rio Negro basin, reaching a maximum known size of $16.6 \mathrm{~mm}$ SL. The skeleton of Tucanoichthys is characterized by the complete absence of ten skeletal elements and marked reduction in size and/or complexity of others, especially those elements associated with the cephalic latero-sensory canal system. Missing elements in the skeleton of Tucanoichthys include those that develop relatively late in the ossification sequence of the non-miniature characiform Salminus brasiliensis, suggesting that their absence in Tucanoichthys can be explained by a simple scenario of developmental truncation. A number of the reductions in the skeleton of Tucanoichthys are shared with other miniature characiforms, most notably species of Priocharax and Tyttobrycon, the latter a putative close relative of Tucanoichthys based on molecular data.
\end{abstract}

\section{Keywords}

developmental truncation, miniaturization, Neotropics, Priocharax, skeleton, Tyttobrycon

\section{Introduction}

Miniaturization, the evolution of extremely small adult body size, is a common phenomenon among freshwater fishes, especially in the Neotropics from where over 200 miniature species $(\leq 26 \mathrm{~mm}$ in standard length [SL] sensu Weitzman and Vari 1988) are already known (Toledo-Piza et al. 2014) and new species continue to be discovered annually (e.g., Henschel 2016; Mendonça et al. 2016; Carvalho et al. 2016, 2017; Calegari and Reis 2017; Pastana et al. 2017; Valdesalici and Nielsen 2017; Caires and Toledo-Piza 2018; Camelier et al. 2018; Jerep et al. 2018; 

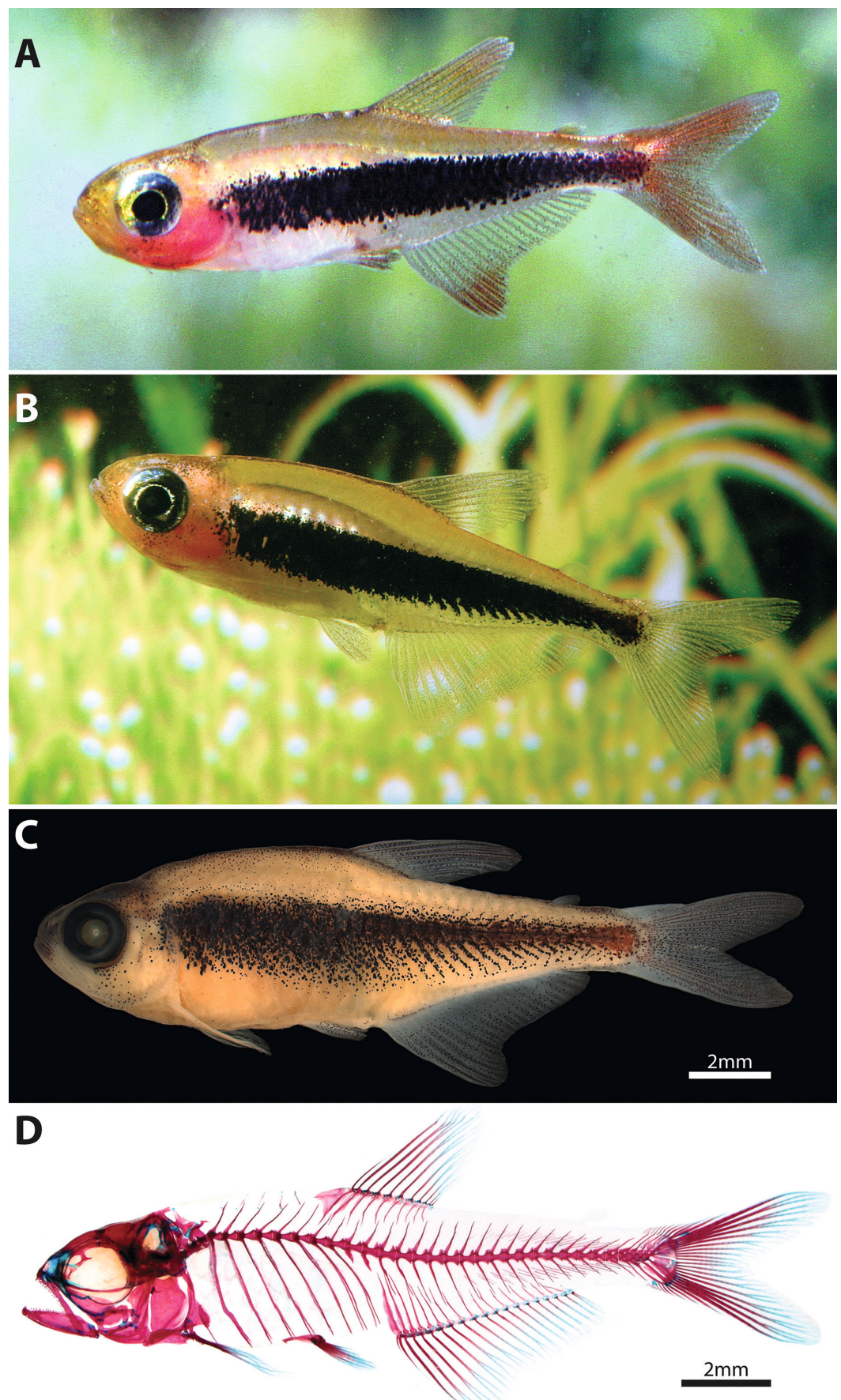

Figure 1. Tucanoichthys tucano. A. Male in life, photographed in aquarium, not measured, not preserved (photo by F. Schäfer). B. Female in life, photographed in aquarium, not measured, not preserved (photo by F. Schäfer). C. TCWC 20316.02, 15.2 mm SL, alcohol preserved specimen. D. TCWC 20316.01, $15.5 \mathrm{~mm} \mathrm{SL}$, c\&s specimen, lateral view of whole skeleton (hyopalatine arch, opercular series and shoulder girdle of right side, and gill arches removed).

Abrahão et al. 2019; Costa et al. 2019; Ohara et al. 2019; Henschel et al. 2020a, 2020b; Mattox et al. 2020, 2021; Lima et al. 2021; Vieira and Netto-Ferreira 2021). Miniaturization is frequently associated with one of two evolutionary processes: (1) a simple evolutionary decrease in body size resulting in miniature versions of larger close relatives (the so-called proportional dwarves of Gould [1971]); and (2) shifts in the relative timing of gonadal development in relation to somatic development (progenesis) resulting in species with developmentally truncated adults that resemble the larval stages of closely related taxa (so-called developmentally truncated miniatures of Rüber et al. [2007]; Britz and Conway [2009]; Britz et al. [2014]). Though the two distinct types of miniature fishes are quite different, both share reductive characters, including for example a reduced number of fin rays, reductions and/or loss of cranial bones, and reductions and/or loss of parts of the cephalic latero-sensory canal system, which contribute to an overall simplification of the skeleton (Myers 1958; Weitzman and Vari 1988). Such reductions can erode the phylogenetic signal in morphological characters, making it challenging to place miniature taxa phylogeneti- 
cally (e.g., see Schaefer et al. 1989; Johnson and Brothers 1993; Siebert 1997; Britz et al. 2014; Mattox et al. 2016).

One such example of a miniature Neotropical fish species of uncertain phylogenetic placement is Tucanoichthys tucano Géry and Römer (Fig. 1), a tiny characid fish described in the late nineties as a new genus and species from the Rio Uaupés, upper Rio Negro basin (Amazonas, Brazil) (Géry and Römer 1997). Individuals of $T$. tucano reach a maximum recorded length of $16.6 \mathrm{~mm}$ SL (Géry and Römer 1997) and exhibit a number of reductive characters, including reduction and loss of parts of the cephalic latero-sensory canal system, a greatly reduced lateral-line canal on the body (restricted to only a few scales), and the absence of some of the infraorbital bones. In their study, Géry and Römer (1997) discussed the putative relationships of $T$. tucano, but refrained from assigning their new species to any of the available subfamilies of the Characidae pending a more detailed phylogenetic study. They preferred to consider Tucanoichthys as incertae sedis within Characidae, a view that has generally been followed in subsequent publications that deal with the Neotropical freshwater fish fauna (e.g., Lima et al. 2003; van der Sleen and Lima 2018). However, a recently published molecular phylogenetic study of the Characoidea recovered Tucanoichthys in a sister group relationship with Tyttobrycon Géry inside of a larger clade of characids (Melo et al. 2021). Tyttobrycon currently comprises six species of different looking miniature characids (ranging in size from 16.9-22.6 mm SL; Toledo-Piza et al. 2014; Abrahão et al. 2019) and the finding of a close relationship between this group and Tucanoichthys deserves further investigation when detailed morphological information is available for both Tyttobrycon and Tucanoichthys.

To provide further information on Tucanoichthys, and the anatomy of miniature characids more generally, we present a detailed overview of the skeleton of T. tucano. We assess the effects of miniaturization on its skeleton, focusing to answer whether Tucanoichthys is developmentally truncated and, if so, estimate the level of developmental truncation by mapping bone absences in T. tucano onto an ossification sequence available for a non-miniature relative (Mattox et al. 2014) following the approach suggested by Britz and Conway (2009). Though a formal phylogenetic analysis is beyond our scope, we also provide comments on putative relationships of Tucanoichthys, from a morphological phylogenetic perspective, based on our findings.

\section{Methods}

Specimens used in this study were obtained independently from both the Brazilian and US ornamental fish trade. As such, detailed information on the geographic origin of the material is not available. Specimens were cleared and double stained for bone and cartilage following Taylor and van Dyke (1985). Specimens were generally dis- sected following the protocol of Weitzman (1974). To facilitate photography of select parts of the skeleton, we chose to dissect one specimen in a non-traditional way involving removal of the neurocranium from the vertebral column, removal of the Weberian ossicles from the vertebral column, and removal of the pectoral fin and radials from the remainder of the shoulder girdle (following Mattox et al. 2014; Britz and Conway 2016; Conway et al. 2017). Specimens or their dissected parts were examined and photographed with a Zeiss Discovery V20 stereomicroscope equipped with a Zeiss Axiocam digital camera. Unless otherwise noted in the text, osteological terminology follows that of Weitzman (1962), as updated by Mattox et al. (2014). The total number of vertebrae includes the four vertebrae of the Weberian apparatus as separate elements. The compound ural centrum was counted as a single vertebra. The gill-raker at the junction of the ceratobranchial and epibranchial is considered as the posteriormost gill-raker on the lower branch of the gill arch. Pseudotympani were exposed by skin removal at the humeral region to reveal the muscular structure around the aperture. Terminology of the pseudotympanum follows Malabarba (1998) except for rib numeration, which follows Mattox and Toledo-Piza (2012).

To determine whether Tucanoichthys tucano is developmentally truncated, and if so, evaluate its level of developmental truncation, we examined bone absences in reference to the ossification sequences of the non-miniature characiform Salminus brasiliensis (Cuvier) (available from Mattox et al. 2014), following the methodology of Britz and Conway (2009) and Mattox et al. (2016).

Material examined as part of this study is housed in the Laboratório de Biologia e Genética de Peixes, Departamento de Morfologia, Instituto de Biociências, Universidade Estadual Paulista "Júlio de Mesquita Filho", Campus de Botucatu, São Paulo, Brazil (LBP), Museu de Zoologia da Universidade de São Paulo, São Paulo, Brazil (MZUSP), and the Biodiversity Research and Teaching Collections, Texas A\&M University, College Station, USA (TCWC).

Tucanoichthys tucano: LBP 18388, 3 (2 c\&s), 15.6-16.4 mm SL; TCWC 20316.01, 4 (c\&s), 14.4-15.9 mm SL; TCWC 20316.02, 7, $12.5-15.9 \mathrm{~mm}$ SL.

Atopomesus pachyodus: LBP 23871, 1, $23.2 \mathrm{~mm} \mathrm{SL}$. Priocharax varii: MZUSP 125787, paratype, 1, $13.5 \mathrm{~mm}$ SL.

\section{Results}

Neurocranium. The chondral and dermal bones of the neurocranium are generally well developed and accompanied by remnants of the chondrocranium, especially in the ethmoid region (Fig. 2, 3A,B). The anterior margin of the cartilaginous ethmoid plate is weakly concave between the ball-like cornua trabeculae. The posterior margin of the ethmoid plate is continuous medially with the well-developed trabecula communis, which extends into 


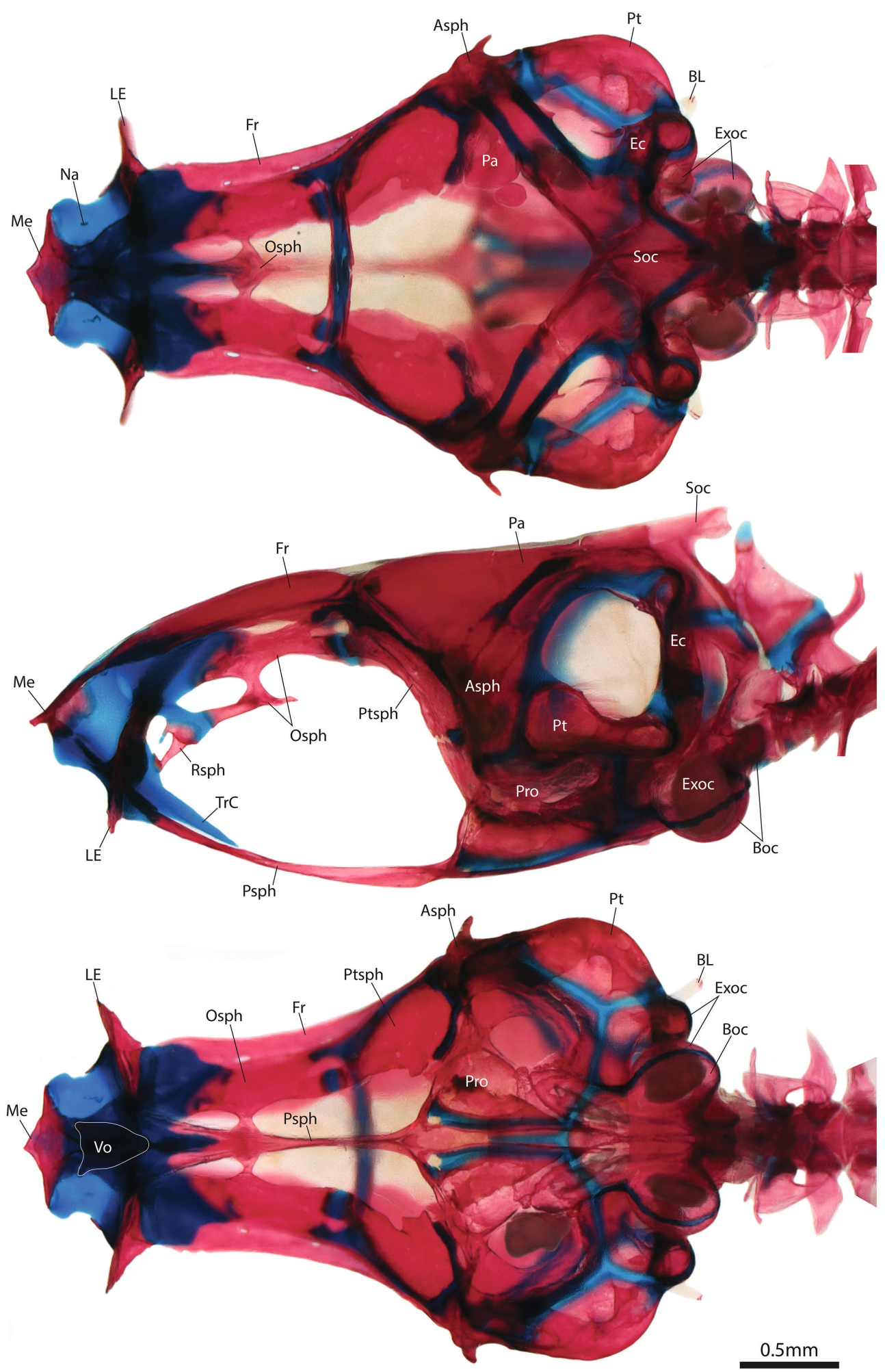

Figure 2. Tucanoichthys tucano, neurocranium of specimen TCWC 20316.01, $14.4 \mathrm{~mm} \mathrm{SL}$, c\&s, in dorsal, lateral and ventral view. Lapillus missing from left side of specimen. Abbreviations: Asph, autosphenotic; BL, Baudelot's ligament; Boc, basioccipital; Ec, epiotic; Exoc, exoccipital; Fr, frontal; LE, lateral ethmoid; Me, mesethmoid; Na, nasal; Osph, orbitosphenoid; Pa, parietal; Pro, prootic; Psph, parasphenoid; Pt, pterotic; Ptsph, pterosphenoid; Rsph, rhinosphenoid; Soc, supraoccipital; TrC, trabecula communis; Vo, vomer.

the orbital region dorsal to the parasphenoid, and laterally with a remnant of the lamina orbitonasalis, at the base of the lateral ethmoid. Ventral to the ethmoid plate, a poorly ossified, roughly shield-shaped vomer (Fig. 2, $3, \mathrm{~B})$ extends from near the anterior margin of the plate posteriorly to the anteriormost tip of the parasphenoid, which inserts between the dorsal surface of the vomer and ventral surface of the trabecula communis. There is no contact between the vomer and mesethmoid along the anteroventral surface of the ethmoid plate. The median 

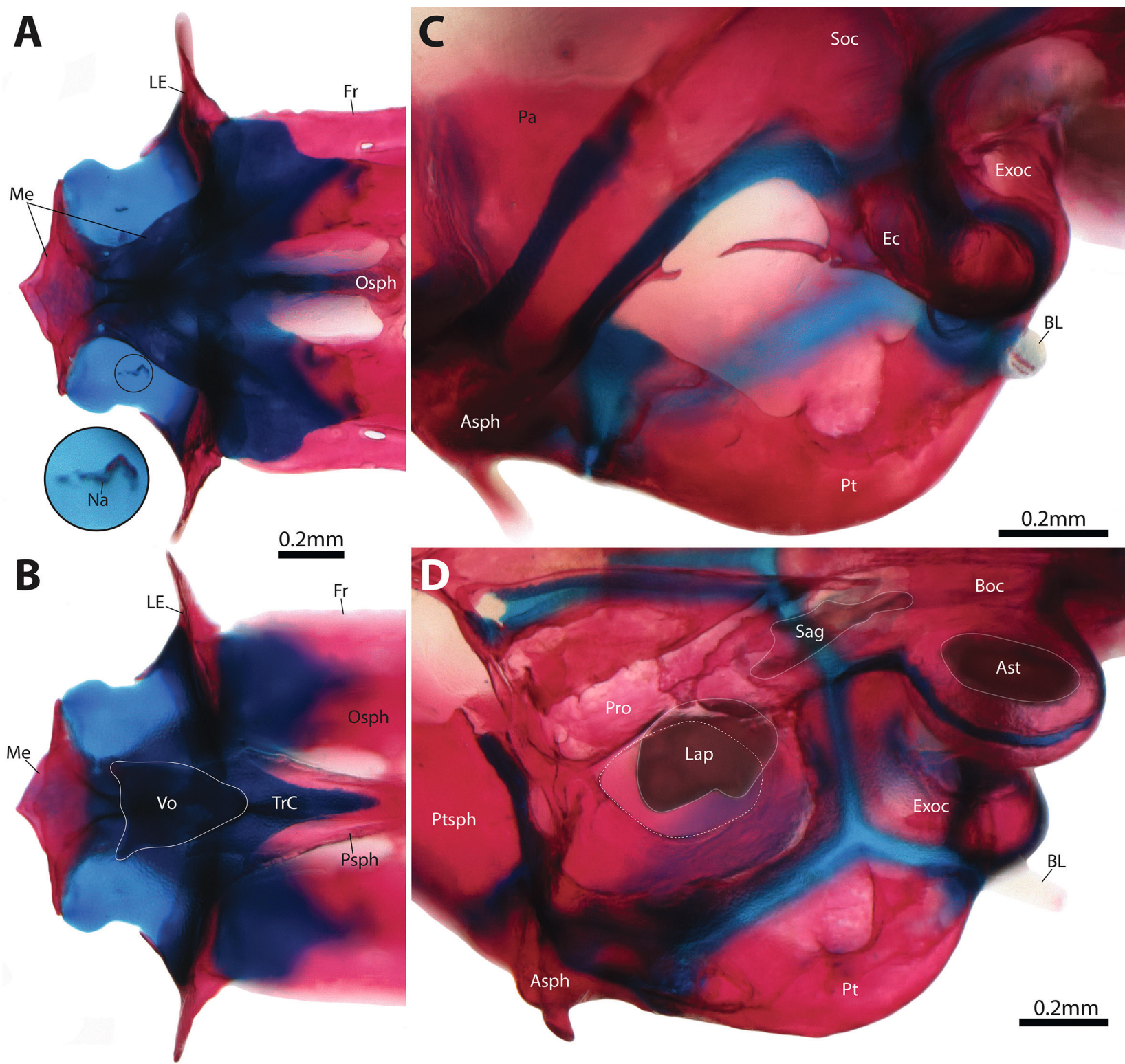

Figure 3. Tucanoichthys tucano, neurocranium of specimen TCWC 20316.01, $14.4 \mathrm{~mm}$ SL, c\&s. A. Ethmoid region in dorsal view. Circular inset shows close up of nasal on left side. B. Ethmoid region in ventral view. Margin of vomer outlined by thin white line. C. Posterolateral part of otic capsule, left side in dorsal view. D. Posterolateral part of otic capsule, right side in ventral view. Otoliths highlighted in light grey, margin outlined by thin grey line. Margin of auditory foramen ventral to lapillus outlined by thin dashed white line. A and B share single scale bar. Abbreviations: Asph, autosphenotic; Ast, asteriscus; BL, Baudelot's ligament; Boc, basioccipital; Ec, epiotic; Exoc, exoccipital; Fr, frontal; Lap, lapillus; LE, lateral ethmoid; Me, mesethmoid; Na, nasal; Osph, orbitosphenoid; Pa, parietal; Pro, prootic; Psph, parasphenoid; Pt, pterotic; Ptsph, pterosphenoid; Sag, sagitta; Soc, supraoccipital; $\operatorname{TrC}$, trabecula communis; Vo, vomer.

mesethmoid is located along the anterior and anterodorsal face of the ethmoid plate and nasal septum. The mesethmoid has a complex shape, closely matching that of median cartilaginous nasal septum at the center of the ethmoid region, separating contralateral nasal capsules. The anteriormost tip of the mesethmoid is drawn out as a short rostral process of membrane bone, which is tightly connected to and wedged between the bases of the ascending processes of the premaxillae. Anterolaterally, the anterior margin of the mesethmoid tapers to a narrow tip, terminating anterior to the ball-like cornua trabecula on the anterolateralmost tip of the ethmoid plate. Posterodorsally, the mesethmoid is U-shaped and surrounds the dorsal part of the medial cartilaginous nasal septum and adjacent sphenethmoid commissure to form the anterior border of the large anterior cranial fontanel (Fig. 2). It is separated from the lateral ethmoid dorsolaterally by the cartilage of the sphenethmoid commissure, but is in contact posteriorly with the anteriormost tip of the frontal, which borders the anterolateral margin of the large anterior cranial fontanel. The lateral ethmoid is well-developed and has replaced almost the entire lamina orbitonasalis positioned between the ethmoid plate and sphenethmoid commissure. The lateral ethmoid extends anteromedially to rim the posteromedial wall of the nasal capsule, but without contact to mesethmoid or vomer, and anterolat- 
erally towards the medial face of the infraorbital 1 , to which it is bound through dense connective tissue. Dorsal to infraorbital 1, the antorbital is also bound to the lateral ethmoid via dense connective tissue but the two bones lack bony contact. The nasal is absent except for a single individual, which exhibits a tiny ossification dorsal to the olfactory capsule that may represent the nasal (Fig. 3A).

Posterior to the ethmoid region of the neurocranium, the lamina orbitonasalis extends posterodorsally reaching the taenia marginalis, which remains cartilaginous at its anterior and posterior portions. A thin lamellar frontal is present from the posterior margin of the mesethmoid to the level of the anterior otic capsule, covering the entire taenia marginalis. Approximately in the middle of its extension, the frontal projects medially along the epiphyseal bar that connects to its contralateral part across the dorsal surface of the neurocranium (Fig. 2). Posterior to the frontal, a small roughly triangular parietal is present on the dorsal surface of the neurocranium. In several individuals, the parietal is fragmented into smaller lamellar pieces of bone (Fig. 2; right side of individual only). Two wide cranial fontanels are present on the roof of the skull, one anterior to the epiphyseal bar delimited by the contralateral frontals and the posterior margin of the mesethmoid, and another posterior to the epiphyseal bar bordered by the contralateral frontals and parietals, and the anterior margin of the supraoccipital (Fig. 2).

The orbitosphenoid lies ventral to the taenia marginalis and projects ventromedially towards its contralateral part. It is bordered anteriorly and posteriorly by patches of cartilage. Ventrally, the orbitosphenoid bears a well-developed process that extends anteroventrally, to connect with the trabecula communis via a short cartilaginous bridge, and posteroventrally, where it terminates as a sharp, spine-like process of membrane bone. The rhinosphenoid is well developed and located in the cartilaginous bridge between the orbitosphenoid and the trabecula communis (Fig. 2). The pterosphenoid is a thin lamellar bone that rims the posterodorsal surface of the orbital cavity. It articulates with the orbitosphenoid and frontal, anteriorly and dorsally, and the autosphenotic, posteriorly. A large foramen is located between the orbitosphenoid and pterosphenoid, and another smaller foramen is present at the center of the pterosphenoid. The autosphenotic articulates with the pterosphenoid anteriorly, the prootic ventromedially, the frontal and parietal dorsally and the pterotic posteriorly. It is surrounded by remains of cartilaginous tissue and bears a short and acute ventrolateral projection that serves as an attachment site for the dilatator operculi. The autosphenotic makes up a large part of the anterior semicircular canal of the inner ear. Posterior to the autosphenotic, the pterotic forms the lateral surface of the otic capsule and composes a large portion of the horizontal semicircular canal of the inner ear. There is no sign of sensory canal ossification along the pterotic, which as such may comprise only the autopterotic. The prootic contributes more than one-half to the floor of the otic capsule and is pierced by approximately seven foramina of various sizes (Fig. 2). The auditory foramen, the largest aperture in the prootic, covers a large portion of the ventral surface of the otic capsule (Fig. 3D). The parasphenoid is a median, thin and elongate bone that extends from the posterior margin of the vomer at the base of the trabecula communis to the anterior portion of the basioccipital between the contralateral prootics (Fig. 2).

The supraoccipital is the posteriormost bone in the roof of the neurocranium. Its anterior margin forms the posterior border of the post-epiphyseal fontanel while its posterior margin projects into a short supraoccipital crest (Fig. 2). The epiotic is a vertical bone surrounding the posterior semicircular canal. It exhibits only a poorly developed anterolateral arm, which does not divide the posttemporal fossa into two apertures as is common in other characiforms (Fig. 3C). The exoccipital forms the posterolateral wall of the otic capsule in the region of the lagena (Fig. 2, 3D). Together with the supraoccipital, it contributes to the margin of a large occipital foramen located lateral to the foramen magnum. The median basioccipital lies ventral to the exoccipital forming the posterior floor of the neurocranium. The intercalar is missing. There is no sign of formation of laterosensory canals in any bones of the neurocranium.

Hyopalatine arch, jaws and opercular series. The hyopalatine arch comprises hyomandibular, symplectic, quadrate, metapterygoid, ectopterygoid, endopterygoid, and autopalatine (Fig. 4A). The hyomandibular is a vertically oriented bone, with an anterior narrow flange of membrane bone. It connects to the neurocranium through a dorsal cartilaginous head, articulating with the anterolateral corner of the otic capsule along the autosphenotic and pterotic. A second smaller cartilaginous head is located along the posterior margin of the hyomandibular, approximately one-fourth of the length from its dorsal tip, and articulates with the articular socket on the opercle. A small foramen for the passage of the hyomandibular branch of the facial nerve pierces the medial surface of the dorsal portion of the hyomandibular. The symplectic is rod-shaped and is separated from the hyomandibular and interhyal by a small remnant of the hyosymplectic cartilage. It is partially covered laterally by the posteroventral process (sensu Arratia and Schultze 1991) of the quadrate. Remnants of the palatoquadrate cartilage also persist in adults between the autopalatine, quadrate, and metapterygoid. The metapterygoid is a thin, axe-shaped bone with three cartilaginous articular heads, including a posterodorsal head, posteroventral head, and anterior head. The posterodorsal head of the metapterygoid extends posteriorly towards the membranous flange on the anterior edge of the hyomandibular. The posteroventral and anterior heads of the metapterygoid approach the posterior and dorsal articular heads of the quadrate, respectively, with which they are connected via remnants of the palatoquadrate cartilage. The shape of the quadrate mirrors that of the metapterygoid. Together, the two bones encircle a large metapterygoid-quadrate fenestra typical of characiforms (Fink and Fink 1981). The laminar endopterygoid is a large roughly oval to tear-shaped bone in lateral view, contributing to the ventromedial surface of the orbital cavity, dorsal to the palatoquadrate cartilage. A 

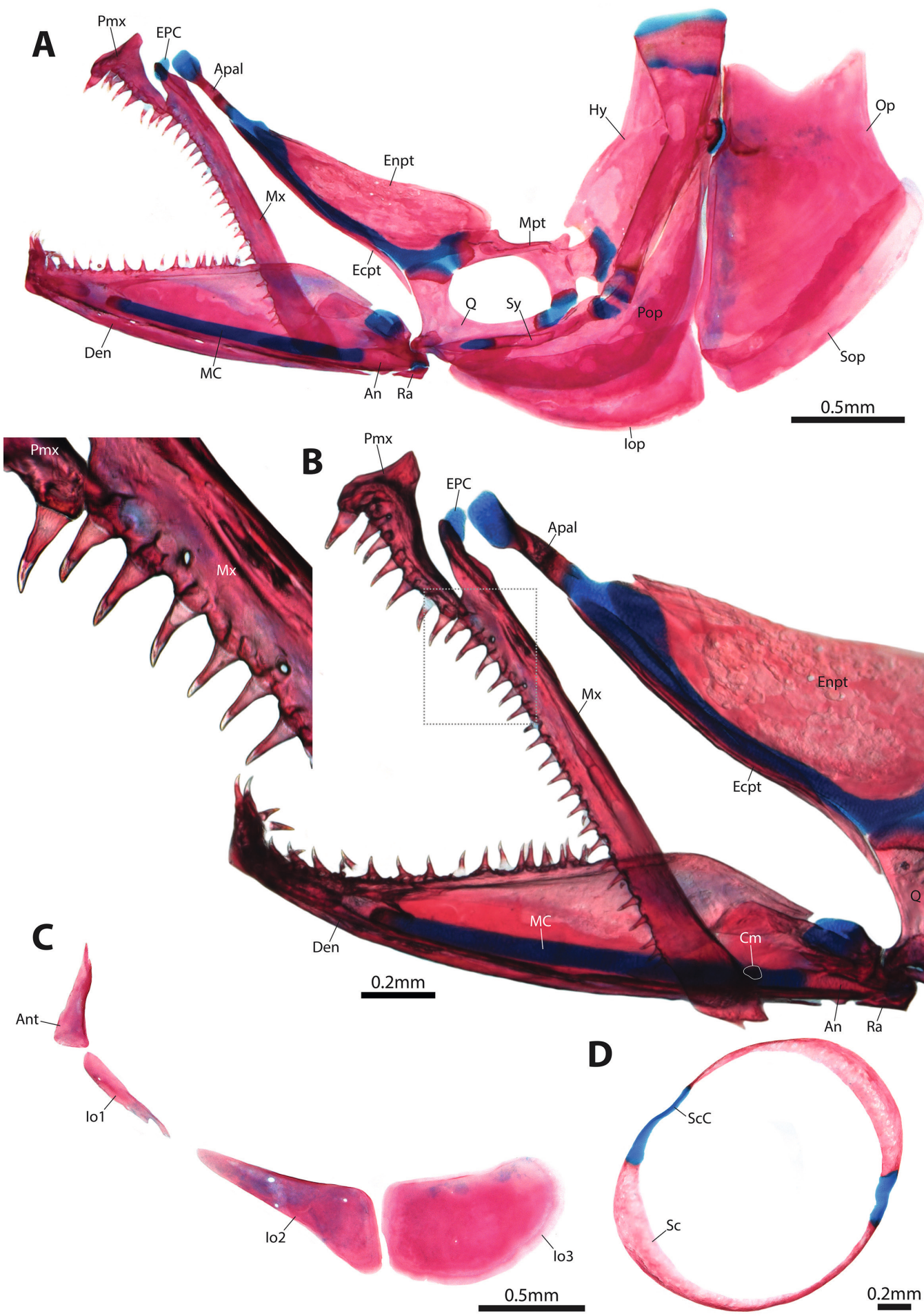

lop
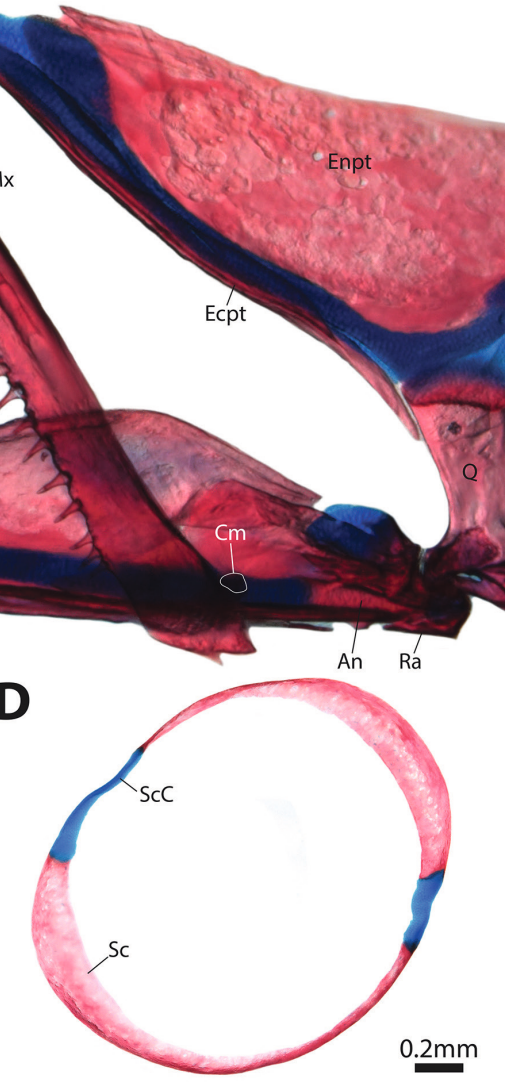

Figure 4. Tucanoichthys tucano, specimen TCWC 20316.01, $14.4 \mathrm{~mm}$ SL, c\&s. A. Hyopalatine arch and opercular series, right side in lateral view (image reversed). B. Jaws and anterior part of palatoquadrate. Margin of coronomeckelian outlined by thin white line. Inset image shows close up of upper jaw teeth at junction of premaxilla and maxilla (area surrounded by box with thin grey dashed line). C. Infraorbital bones, right side in lateral view (image reversed). D. Sclerotic ring, right side in lateral view. Abbreviations: An, anguloarticular; Ant, antorbital; Apal, autopalatine; Cm, coronomeckelian; Den, dentary; Ecpt, ectopterygoid; Enpt, endopterygoid; EPC, Ethmo-Palatine cartilage; Hy, hyomandibular; Iop, interopercle; Io1-3, infraorbitals 1-3; MC, Meckel's cartilage; Mpt, metapterygoid; Mx, maxilla; Op, opercle; Pmx, premaxilla; Pop, preopercle; Q, quadrate; Ra, retroarticular; Sc, sclerotic; ScC, sclerotic cartilage; Sop, subopercle; Sy, symplectic.

long and narrow edentulous ectopterygoid is located ventral to the endopterygoid and bridges the gap between the posterior tip of the autopalatine and the anterodorsal head of the quadrate. The autopalatine is a short, flattened bone located at the anterior tip of the palatoquadrate cartilage. A small remnant of the palatoquadrate cartilage located anterior to the autopalatine articulates with the ethmoid plate medially, and a small independent cartilage (ethmo-pala- 
tine cartilage sensu Fink and Fink 1981) located adjacent to the ascending process of the maxilla, anterolaterally.

The lower jaw comprises Meckel's cartilage, and the bones anguloarticular, coronomeckelian, retroarticular, and dentary (Fig. 4A, B). The dentary is widest posteriorly, tapering towards the symphysis to almost one-half the width of the posterior portion. It has a single series of 15-20 small conical teeth, the two or three anteriormost the largest. The tips of the teeth are slightly curved lingually. The replacement teeth develop extraosseously in the surrounding gum tissue, unlike replacement teeth in many characiforms with multicuspid teeth. The coronoid process of the dentary is a low dome along the dorsal edge of the posterior part of the dentary, following the anterodorsal margin of the anguloarticular. There is no trace of a bony lateral-line canal on the dentary. The dentary has five pores along the anterior portion of its ventral surface, likely associated with nerves innervating neuromasts homologous to canal neuromasts in those species in which an enclosed lateral line canal is present along the dentary. The anguloarticular is approximately trapezoidal in lateral view, with an anterior ventral expansion fitting into the posteroventral margin of the dentary, leaving a small gap between the two bones in some specimens. The anguloarticular articulates with the quadrate posteriorly, and is separated from the tiny triangular retroarticular by a small cartilaginous nodule posteroventrally. The mandibular fossa formed on the medial surface of the dentary and anguloarticular is shallow and houses the long cylindrical remnant of Meckel's cartilage. A small circular to triangular coronomeckelian is located at the posterior end of Meckel's cartilage.

The upper jaw comprises premaxilla, maxilla, and ethmo-palatine cartilage. The premaxilla is thin and has a short ascending process articulating with the mesethmoid. There are nine small conical premaxillary teeth of similar size, with tips slightly curved lingually. The elongate maxilla is slightly wider at the posterior end and gently tapers anteriorly. It bears a single series of 18-21 conical teeth along the entire ventral margin of the bone, similar in size and shape to those of the premaxilla. The short anterior process of the maxilla is edentulous and extends along the posterodorsal margin of the premaxilla. A tiny nodule of cartilage, ethmo-palatine cartilage (sensu Fink \& Fink 1981), is located medial to the anterior process of the maxilla. The ethmo-palatine cartilage appears to be located inside of a ligamentous connective tissue extending between the head of the autopalatine and the maxilla.

The four bones of the opercular series are thin and poorly ossified (Fig. 4A). The opercle is a roughly shieldshaped bone. It is most heavily ossified around the articular condyle with the hyomandibular, from where a short medial crest extends posteriorly on the medial face of the bone. A large notch is present along the dorsal margin of the bone, leaving the upper part of the branchial chamber uncovered by bone. The posterior margin of the opercle is approximately round. The subopercle is thin and elongate, bordering the ventral margin of the opercle, by which it is partially overlapped laterally. The preopercle is roughly boomerang-shaped with vertical and horizontal arms. The anterior tip of the horizontal arm is overlapped laterally by the posteroventral arm of the quadrate. The vertical arm extends dorsally to terminate as a pointed tip lateral to the hyomandibular, approximately at the level of the articular condyle of the opercle. A poorly developed flange of bone on the lateral face of the preopercle creates a shallow trough to accommodate the short preopercular portion of the preoperculo-mandibular lateral line canal. This open canal is the only bony component of the cephalic lateral line system in Tucanoichthys. The interopercle is located ventral to the preopercle. It is widest posteriorly and tapers anteriorly towards the site of attachment of the interoperculo-mandibular ligament.

Infraorbital Series and Sclerotic bones. There are four bones in the infraorbital series, including the antorbital and infraorbitals 1, 2, and 3 (Fig. 4C). All are thin and plate-like, without surface sculpturing or signs of sensory canals. Small circular openings on the surface of each of the three infraorbital bones likely represent nerve foramina associated with innervation of putative infraorbital neuromasts (not investigated). The triangular antorbital is located anterior to the lateral ethmoid. It is broadest ventrally and gradually tapers in width dorsally, terminating at a sharp point. Infraorbital 1 (lachrymal) is narrow, with an irregular ventral margin, located below the anteroventral margin of the orbit, between the ventral tip of the antorbital, the anterolateral edge of the lateral ethmoid and the posterior edge of the maxilla. Infraorbital 2 is twice as long as infraorbital 1 and approximately triangular, narrowest at its anterior tip. Infraorbital 3 is the largest of the three infraorbital bones. Anteriorly, it shows a straight vertical margin, which is equal in depth and in close proximity to the posterior part of infraorbital 2. The ventral and posterior margins are weakly rounded. Infraorbitals 4, 5, and 6 and the supraorbital are absent.

Two thin sclerotic bones surround the eye (Fig. 4D), separated by two narrow strips of cartilage, one located at the anterodorsal part of the eye and the other at its posteroventral part.

Hyoid bar, Urohyal, and Branchial Arches. The hyoid bar comprises dorsal hypohyal, ventral hypohyal, anterior ceratohyal, posterior ceratohyal, and interhyal (Fig. 5H). The dorsal hypohyal is small and cone shaped, capping the anterior end of the ceratohyal cartilage, without bony contact to surrounding bones. It bifurcates posteriorly towards the anterior portion of the anterior ceratohyal which is also bifurcated, resulting in a small round opening between these two bones. The ventral hypohyal is larger and more heavily ossified than the dorsal hypohyal. Its ventromedial surface connects to a ligament from the urohyal. The anterior ceratohyal is elongate, broader at its posterior end, tapering towards the middle portion, and slightly widening towards its anterior end. Anterior and posterior ceratohyals are separated by a thin strip of cartilage. The posterior ceratohyal is approximately trapezoidal in lateral view and is anteroposteriorly crossed by the canal opening into the anterior ceratohyal. A canal from the posterior ceratohyal crosses the posterodorsal portion 




Figure 5. Tucanoichthys tucano, specimen TCWC 20316.01, $14.4 \mathrm{~mm} \mathrm{SL}$, c\&s (A-G), and LBP 18388, $15.6 \mathrm{~mm}$ SL, c\&s (H). A. Gill arches in dorsal view. B. Gill rakers articulating with anterior edge of hypobranchial 2, left side in dorsal view. C. Ventral gill arches in dorsal view. D. Dorsal gill arches, right side, dorsal view (image reversed). E. Dorsal gill arches, right side, ventral view. F. Upper pharyngeal teeth associated with pharyngobranchial 3 and 4 tooth plates, right side, ventral view. G. Lower pharyngeal teeth associated with ceratobranchial 5, right side, dorsal view. H. Hyoid bar, right side, and urohyal, in lateral view (image reversed). Gill filaments removed in B-G. C-E share single scale bar. Abbreviations: ACh, anterior ceratohyal; BB1-3, basibranchial 1-3; BB4-5C, basibranchial 4-5 cartilage; BR, branchiostegal rays; CB1-5, ceratobranchial 1-5; DHh, dorsal hypohyal; EB1-4, epibranchials 1-4; EB5C, epibranchial 5 cartilage; GF, gill filament; GR, gill raker; Ih, interhyal; PB1-3, pharyngobranchial 1-3; PB4C, pharyngobranchial 4 cartilage; PB3-4TP, pharyngobranchial 3-4 tooth plate; PCh, posterior ceratohyal; Uh, urohyal; UPEB4, uncinate process of epibranchial 4; VHh, ventral hypohyal. 
of the anterior ceratohyal, opening on its posterodorsal margin. The posterior ceratohyal has a medial opening in the middle of this canal. A cylindrical interhyal articulates with the posterodorsal margin of the posterior ceratohyal in the region of the suspensorium between hyomandibular and symplectic. There are four branchiostegal rays, the two anteriormost with approximately the same width along their lengths and articulating with the ventromedial margin of the anterior ceratohyal. The third and fourth branchiostegal rays are slightly wider at their proximal ends and articulate with the ventral portions of the lateral surfaces of the anterior and posterior ceratohyals, respectively. The flattened triangular urohyal connects via ligaments to the ventral hypohyal anteriorly and to the aponeurosis that covers the sternohyoideus laterally posteriorly.

The basihyal is triangular, with its anterior end wider than its posterior tip articulating with basibranchial 1 . Anterior to the cartilaginous anterior tip of the basihyal are two separate cartilages, which are separate from the basihyal cartilage but appear to be located within a connective tissue that spans all three cartilages. There are three rod-like basibranchials along the ventral midline of the branchial arches (Fig. 5A,C). They are separated from each other by remnants of the cartilaginous anterior copula. Basibranchial 1 is the shortest and located posterior to the basihyal between the paired hypobranchial 1. Basibranchial 2 and 3 are almost twice the length of basibranchial 1, with hypobranchial 2 articulating with the posterolateral margins of basibranchial 2 and hypobranchial 3 articulating with the lateral margins of basibranchial 3. The posterior tip of the latter bone is dorsally covered by the cartilaginous bridge formed between the contralateral hypobranchial 3 and the anterior end of the posterior copula, which remains cartilaginous. The posterior copula (= basibranchial 4 cartilage) is elongate and well developed, narrower anteriorly and broader towards its posterior end. It articulates with the pair of ceratobranchials 4. Basibranchial 5 cartilage, a short and narrow rod of cartilage is present posterior to the posterior copula near the articulation with ceratobranchials 5. There are three pairs of hypobranchials, their ossification covering less of the cartilage posteriorly. Hypobranchial 1 is the largest with cartilage only at its ends. It carries two elongate gill rakers along its leading edge (Fig. 5A,B). Hypobranchial 2 ossification occupies approximately half of its cartilage precursor and also supports two elongate gill rakers along its leading edge. Hypobranchial 3 has an anterior horn-shaped process and carries one or two relatively short gill rakers on its leading edge. A separate hypobranchial 4 cartilage is not present. Ceratobranchials 1-4 are rod-shaped with ceratobranchial 1 the longest, and their length gradually decreasing posteriorly. Ceratobranchials $1-3$ have a series of 7-10 elongate gill rakers along their leading edges, with the rakers on ceratobranchial 1 more elongate and rakers of posterior ceratobranchials gradually decreasing in size posteriorly. Ceratobranchial 4 has a series of 7 short gill rakers on its leading edge. Ceratobranchials 3 and 4 each support a series of 8-12 very short gill rakers on their trailing edges. Ceratobranchial 5 is also a rodshaped bone but with a triangular flange of membrane bone along its trailing edge forming the lower pharyngeal tooth plate. This tooth plate is covered by $20-30$ small conical teeth concentrated along the distal margins of the plate. Ceratobranchial 5 supports a series of 10-12 short gill rakers along its leading edge. All ceratohyals are proximally and distally tipped in cartilage.

Epibranchials 1-4 are elongate, with dorsal uncinate processes that serve as sites of attachment for branchial muscles, better developed on epibranchials 3 and 4. Proximal and distal tips of the epibranchials, and the distal tips of the uncinate processes are all cartilaginous. All epibranchials have a series of 5-6 elongate gill rakers on their leading edges, and epibranchials 1-3 also have a series of 3-4 short gill rakers on their trailing edges. A short epibranchial 5 cartilage is present near the distal tip of epibranchial 4. There are four pharyngobranchials, with pharyngobranchials 1-3 ossified. The triangular pharyngobranchial 1 is the least developed of the three and articulates with the ventral surface of the neurocranium. Pharyngobranchials 2 and 3 are also triangular and support a series of 1-3 short gill rakers on their leading edges. Pharyngobranchial 4 is a large cartilaginous plate that supports the upper pharyngeal toothplate along with the anterior portion of epibranchial 4. This toothplate is divided into two units in all specimens examined (Fig. $5 \mathrm{~F}$ ) and evenly covered by more than 30 small conical teeth. Another upper pharyngeal toothplate with only 3-4 teeth is associated with pharyngobranchial 3.

Pectoral Girdle. There are eight to ten pectoral-fin rays (i,6,i, i,6,ii or i,7,ii). The posttemporal is thin and elongate with a pointed dorsal tip terminating on the posterodorsal surface of the skull close to the junction between the supraoccipital and parietal. There is no direct bony contact between the posttemporal and the skull in most specimens. In two specimens, there is simple contact between the epiotic and the medial face of the posttemporal, at the base of the poorly developed epiotic bridge. Ventrally, where it contacts the dorsal tip of the supracleithrum, the posttemporal is slightly broader. The supracleithrum is elongate and thin, with its dorsal tip slightly curved behind the ventral tip of the posttemporal (Fig. 6A). The supracleithrum is expanded laterally towards its ventral tip, where Baudelot's ligament connects the anterior surface of the bone to the ventral surface of the basioccipital, anterior to the lagenar capsule. There are no laterosensory canals in the posttemporal or supracleithrum. The cleithrum is the largest bone in the pectoral girdle, curved anteroventrally following the posterior margin of the branchial chamber. It has a thin but large flange of membrane bone along its posterior face forming an approximately triangular ledge. A medial blade of membrane bone is borne along the ventral half of the cleithrum. The cleithrum articulates with its counterpart in the ventral midline. Ventromedially, the cleithrum articulates with the coracoid which is a flat bone that extends along the anteroventral part of the cleithrum. The coracoid is well-developed and bears a ventral flange of membrane bone that articulates 

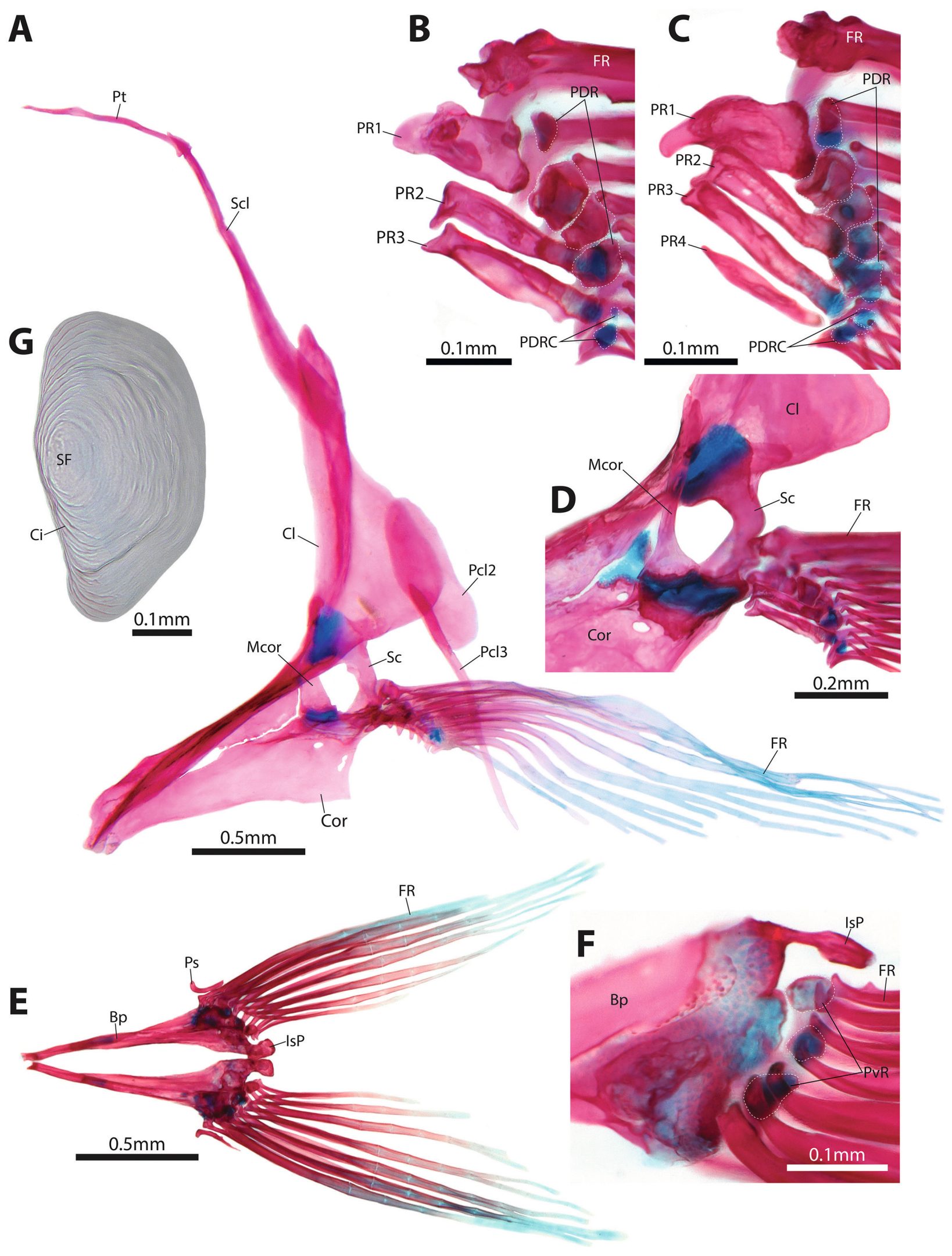

Figure 6. Tucanoichthys tucano, specimen LBP 18388, $15.6 \mathrm{~mm} \mathrm{SL}$, c\&s (A), and TCWC 20316.01, $14.4 \mathrm{~mm} \mathrm{SL} \mathrm{(B,} \mathrm{D,} \mathrm{E,} \mathrm{G),}$ $14.6 \mathrm{~mm}$ SL (C, F), c\&s. A. Pectoral fin and girdle, right side, lateral view (image reversed). B. Dissected pectoral radials, right side, lateral view (image reversed). C. Dissected pectoral radials, right side, lateral view (image reversed). D. Elements of scapulo-coracoid cartilage, right side, medial view. E. Pelvic fin and girdle, dorsal view. F. Pelvic radials, right side, oblique ventral view (image reversed). G. Scale from side of abdomen. Pectoral distal radials and Pectoral distal radial cartilages (B, C,) and pelvic radials (F) outlined by thin white dashed line. Abbreviations: Bp, basipterygium; $\mathrm{Ci}$, circulus; $\mathrm{Cl}$, cleithrum; Cor, coracoid; FR, fin ray; IsP, ischiac process; Mcor, mesocoracoid; Pcl2-3, postcleithrum 2-3; PDR, pectoral distal radial; PDRC, pectoral distal radial cartilage; PR1-4, pectoral radial 1-4; Ps, pelvic splint; Pt, posttemporal; PvR, pelvic radial; Sc, scapula; Scl, supracleithrum; SF, scale focus. 
with its counterpart in the ventral midline. Posteriorly, the coracoid has two small openings in the bone. The scapula is approximately L-shaped and delimits laterally a large opening whose medial margin is formed by the cleithrum. The dorsal arm and the tip of the anterior arm of the scapula are less developed and remnants of the scapulocoracoid cartilage are present. The scapula articulates with the enlarged head of the first pectoral-fin ray and the base of pectoral radial one. The triangular mesocoracoid articulates dorsally with the medial face of the cleithrum and ventrally with the coracoid and scapula. It retains a large cartilaginous cap ventrally at the point of contact with the coracoid and scapula. There are four proximal pectoral radials that articulate with the posterior margins of the scapula and coracoid (pectoral radial 1) or coracoid (pectoral radials 2-4), respectively. Pectoral radial 1 is the largest of the four radials and has a slightly bifurcated base via which it articulates with the shoulder girdle. Pectoral radial 1 is well ossified endochondrally. The remaining pectoral radials $(2-4)$ retain cartilaginous distal tips. In one of the individuals examined (TCWC 20316.01, $14.4 \mathrm{~mm} \mathrm{SL}$ ), pectoral radial 4 is absent (Fig. 6B). There are six or seven roughly spherical pectoral distal radials, the four or five anteriormost endochondrally ossified and the two or three posteriormost cartilaginous (Fig. 6B,C). There are two postcleithra, including an upper elliptical element (postcleithrum 2) that is attached to the posteroventral flange of membrane bone on the cleithrum, and a more ventral, rod-like element (postcleithrum 3), which articulates with the lower half of the anterior and medial margin of postcleithrum 2 (Fig. 6A). Postcleithrum 1 and extrascapular are absent.

Pelvic Girdle. There are seven pelvic-fin rays $(i, 4, \mathrm{ii})$ and a tiny pelvic-splint associated with the upper hemitrichium of the outermost ray. The thin, almost rod-like basipterygium is narrowest anteriorly and tapers slightly towards the broader posterior part of the bone (Fig. 6E). In lateral view, the anterior tip of the basipterygium is located between the distal tip of the sixth and seventh rib (Fig. 1C). The basipterygium has a medial flange of membrane bone posteriorly, which is drawn out posteromedially to form a short ischiac process (Fig. 6E,F). The contralateral ischiac processes abut along the ventral midline, representing the only point of contact between the right and left basipterygia. There are three radial cartilages, which are ossified endochondrally (Fig. 6F). Bony hooks are absent from any of the pelvic-fin rays.

Weberian Apparatus Skeleton. The four anteriormost abdominal vertebrae and associated elements contribute to the Weberian apparatus skeleton (Fig. 7). Centrum 1 is the shortest with the three more posterior centra gradually more elongate. The second centrum bears a large lateral process on its anterior margin. The third centrum has a wide neural arch that supports a lateral transverse process. There is a large gap between the neural arches of the third and fourth centra, partially occupied by a pointed dorsal process from the third centrum. The fourth centrum is almost as long as more posterior centra in the vertebral column and its neural arch is wider and larger than that of the preceding centrum. It carries a neural spine almost half the length of that on subsequent vertebrae. The large supraneural 3 sits above neural arches 3 and 4, separated from them by remnants of the neural complex cartilage, which is wider in its anterior portion. Supraneural 3 has a somewhat triangular shape with a small anterior extension that articulates with the supraoccipital. It also has a rod-shaped dorsal process that reaches towards the dorsal profile of the body.

The claustrum is absent. The scaphium is large and round with a short ascending process and a wide concha scaphii fitting into a notch on the posterior margin of the exoccipital (Fig. 7A). The intercalarium is well developed and L-shaped. Scaphium and intercalarium articulate each via a small nodule of cartilage with centra 1 and 2, respectively, and are linked by the interossicular ligament connecting the posterolateral surface of the scaphium to the distal tip of the manubrium of the intercalarium (Fig, 7B). The triangular tripus is the largest of the Weberian ossicles and articulates with the third centrum through a small cartilaginous process. The tripus has a thin anterior process, the distal tip of which is connected to the intercalarium via an interossicular ligament, and a large triangular transformator process that tapers posteriorly and medially where it sits in the connective tissue of the wall of the anterior chamber of the swimbladder (Fig. 7B). The os suspensorium articulates with the fourth centrum. Its outer arm has a broad flattened flange of membrane bone extending anterolaterally and covering dorsally part of the transformator process of the tripus. The inner arm of the os suspensorium is narrow at its base. It increases slightly in width and twists distally to occupy a vertical position ventral to the centra.

Vertebral Column and Intermuscular Bones. There are 13-15 abdominal and 19-20 caudal vertebrae (Fig. 1C). Except for the centra belonging to the Weberian apparatus and the compound ural centrum, all other centra are approximately hourglass-shaped and similar in size (Fig. 8B-D), with their length gradually shortening from pre-ural centrum 4 to 2 (Fig. 8D). Neural arches and neural spines are present on all post-Weberian vertebrae, with arches located near the anterior portion of each centrum. Poorly developed neural prezygapophyses are present from centrum 6 to almost the last centrum. Small neural postzygapophyses are developed from the $10 / 11^{\text {th }}$ centrum and are better developed caudally. Pre-ural centra 2-5 have the neural zygapophyses and neural arches connected by membrane bone, with the neural spine located more posteriorly in pre-ural centra 2-4 (Fig. 8D). Neural arches are gradually more inclined posteriorly towards the caudal end of the vertebral column, all with a similar size. In the area between the abdominal and caudal parts of the vertebral column there are two or three transitional vertebrae lacking ribs and with open haemal arches, counted herein as abdominal vertebrae (Fig. 8B). Complete haemal arches and spines are present from centrum $14 / 15$ to pre-ural centrum 2, all of similar size, except for the last two haemal spines which are more elongate 

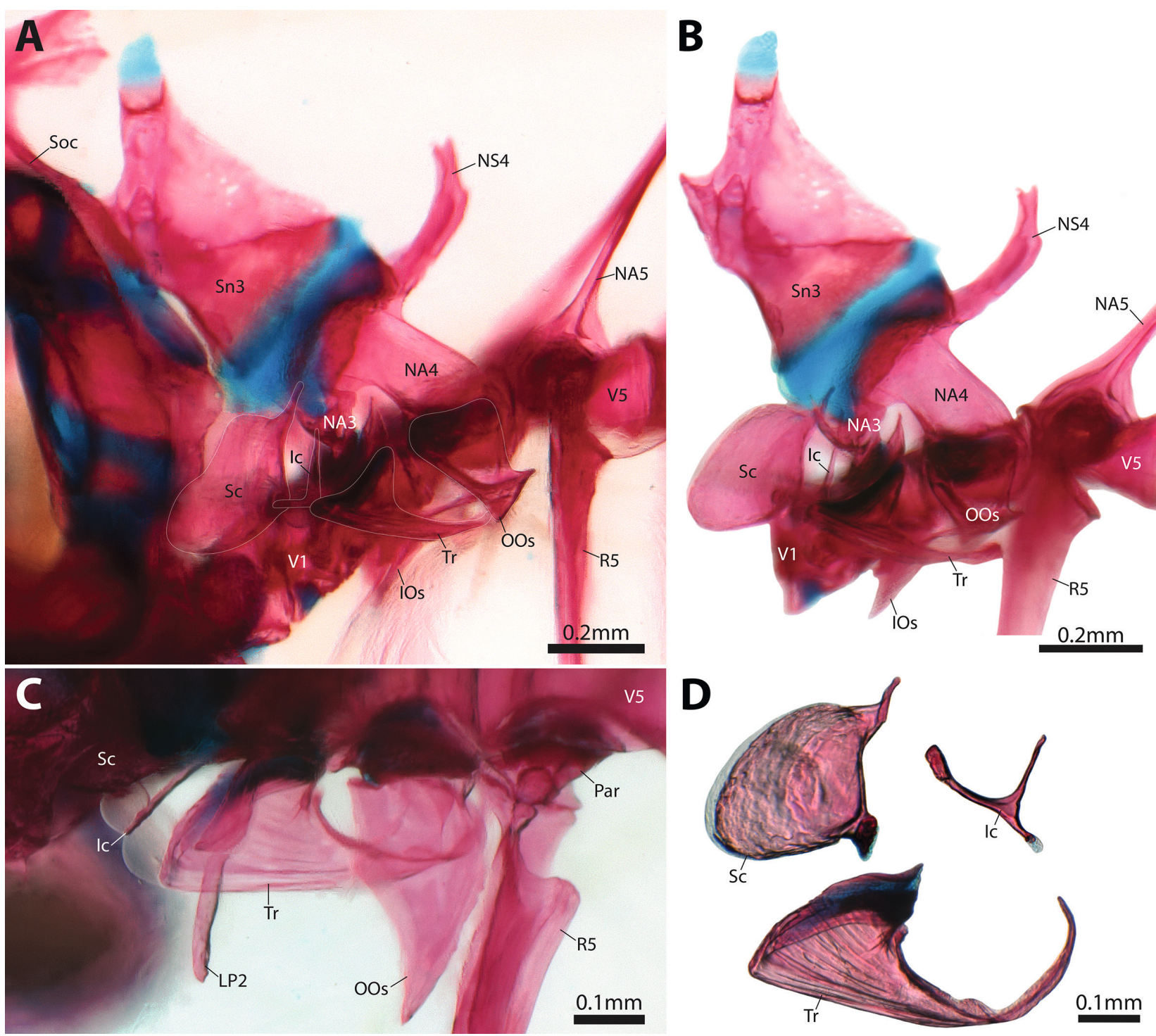

Figure 7. Tucanoichthys tucano, specimen TCWC 20316.01, 14.4 mm SL, c\&s. A. Weberian apparatus, left side, lateral view. B. Weberian apparatus, left side, lateral view, neurocranium separated from vertebral column. C. Same as A, oblique dorso-lateral view. D. Dissected scaphium, intercalarium and tripus of left side. Abbreviations: Ic, intercalarium; IOs, inner arm of the os suspensorium; LP2, lateral process of vertebral centrum 2; NA3-5, neural arch 3-5; OOs, outer arm of the os suspensorium; Par, parapophysis; R5, rib 5; Sc, scaphium; Sn3, supraneural 3; Soc, supraoccipital; Tr, tripus; V1-5, vertebral centrum 1-5.

and laterally flattened distally. Haemal arches and spines are located on the anterior portion of each centrum, except those towards the caudalmost vertebrae, which have haemal arches gradually located more posteriorly along the centrum. As with neural spines, the haemal spines are also gradually more inclined posteriorly towards the caudal fin. Small haemal postzygapophyses are present between centra 13/14-27/28, with the anteriormost more developed. Inconspicuous haemal prezygapophyses are borne on centra 21/22-27/28. There are eight parapophyses and associated ribs, starting on centrum 5 . The anteriormost parapophysis (the fifth) is the largest of the series and the others gradually decrease in size posteriorly. The anteriormost rib (the 5th) is the thickest and longest of the series and the ribs gradually become thinner and shorter towards the posterior part of the abdominal cavity. All ribs are posteroventrally inclined. The 5th rib has a small medial flange of membrane bone near its proximal tip. The remaining ribs carry an anteromedial flange of membrane bone proximally, similar in size and shape to the head of the respective parapophyses with which they articulate. In our material, the number of free supraneurals ranges from 3-5, in association with the neural spines of centra 5-9. In most individuals, the supraneurals are poorly ossified rod-like bones, with cartilaginous tips (Fig. 1A). In one individual, the anteriormost supraneural is represented by a small circular cartilage only (Fig. 8A). Inconspicuous, rod-like epineural and epipleural bones are present on the posterior part of the body only, adjacent to centra $17 / 18$ to the PU4 (Fig. 1C, $8 \mathrm{C}-\mathrm{D}$ ). The elements of both series gradually increase in length and robustness posteriorly, suggesting that each series may develop in a caudal $>$ rostral direction.

Caudal Fin and Caudal Fin Skeleton. There are 19 principal caudal-fin rays $(10+9$ or $\mathrm{i}, 9+8, \mathrm{i})$, nine to ten dorsal 

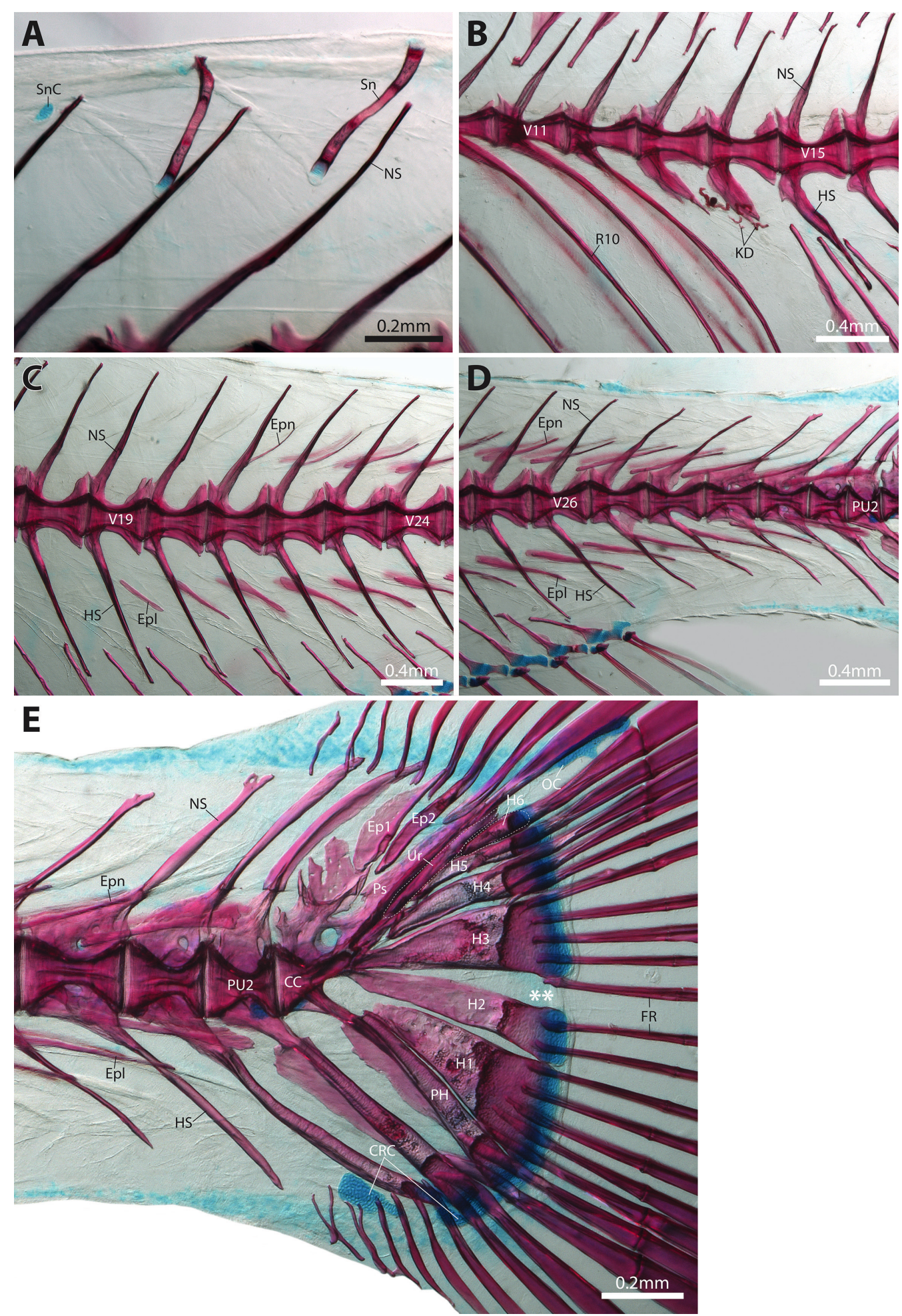

Figure 8. Tucanoichthys tucano, specimen TCWC 20316.01, $14.4 \mathrm{~mm} \mathrm{SL}$, c\&s. A. Supraneural elements associated with neural spines of vertebra 7-9, left side, lateral view. B. Vertebral centra 11-15, left side, lateral view. C. Vertebral centra 18-24, left side, lateral view. D. Vertebral centra 25-31(PU2), left side, lateral view. E. Caudal fin skeleton, left side, lateral view. Margin of uroneural and hypural 6 outlined with thin white line in E. Double white asterisk (**) indicates the position of caudal diastema. Abbreviations: CC, compound centrum; CRC, caudal radial cartilage; En, epineural; Ep, epipleural; Ep1-2, epural 1-2; H1-6, hypural 1-6; HS, hemal spine; KD, calcification of kidney; NS, neural spine; OC, opisthural cartilage; PH, parhypural; PS, pleurostyle; PU2, pleural centrum 2; R, rib; Sn, supraneural; SnC, supraneural cartilage; Ur, uroneural; V11-26, vertebral centrum 11-26.

procurrent rays and eight to nine ventral procurrent rays (Fig. 8E). The principal caudal-fin rays are supported by the pleurostyle, uroneural 2, six hypurals, parhypural and haemal spine of pre-ural centrum 2. Dorsal procurrent rays are supported by the neural spines of pre-ural centra 2, 3 and 4, and two epurals. Ventral procurrent rays are supported by the haemal spines of pre-ural centra 2 and 3 and two small caudal radial cartilages, both associated 
with the distal tip of the haemal spine of pre-ural centrum 3. There are two rod-shaped epurals anterior to the pleurostyle, the first of which bears an anterior flange of membrane bone. The pleurostyle is a robust rod-shaped bone fused to the compound centrum at its base. A flange of membrane bone is borne along its anterodorsal edge which is connected to a larger flange of membrane bone on the dorsal surface of the compound centrum. Uroneural 2 is rod-shaped and contacts the posterior edge of the pleurostyle. The opisthural cartilage is conspicuous at the tip of the notochord. The parhypural is flattened laterally and carries a small flange of membrane bone on its anterior edge. The posterior margin of the parhypural is in close contact with the anterior margin of hypural 1 . There are six hypurals, 1-6, all rimmed with cartilage distally. Hypural 1 is approximately triangular and detached from the compound centrum as is typical in characiforms (Fink and Fink 1981). Hypural 2 is narrower than hypural 1 and fused to the compound centrum. Hypurals 1 and 2 are located ventral to the diastema of the caudal fin. Hypurals 3-6 are dorsal to the diastema. Hypural 3 is a large triangular bone, similar in size and shape to hypural 1, with connection to the posteriormost part of the compound centrum. Hypurals 4-6 are elongate rods of bone. These three hypurals, each sequentially smaller dorsally than the ventrally adjacent element, articulate distally with the posterior edge of the pleurostyle.

Dorsal Fin. The dorsal fin has 11 rays (ii.8.i) supported by 10 pterygiophores (Fig. 9A), so that the first ray is supernumerary. The first dorsal-fin pterygiophore inserts between the neural spines of vertebrae 10 and 11 . The four anterior pterygiophores comprise proximal-middle and distal radials. The remaining pterygiophores include proximal, middle, and distal radials. The distal radials are gradually less ossified caudally, with the two or three posteriormost almost entirely cartilaginous (Fig. 9B,C). The first proximal-middle radial has a well-developed anterior flange of membrane bone surrounding the tip of the adjacent neural spine on vertebra 10 . The remaining proximal-middle or proximal radials show small flanges of membrane bone along both the anterior and posterior margins, with the flanges becoming gradually shorter caudally (Fig. 9A). The dorsal-fin stay is thin and confluent with the distal tip of the last proximal-middle radial. The first pterygiophore supports two unbranched dorsal-fin rays, the anterior of which is half the length of the posterior and in a supernumerary position. The remaining nine pterygiophores each support a single branched dorsal-fin ray in a serial association, except for the posteriormost bearing one unbranched ray. The two anteriormost branched dorsal-fin rays are the longest, with rays gradually becoming shorter caudally.

Anal Fin. The anal fin has 18 pterygiophores supporting 21 fin rays (iii.17.i) (Fig. 9A) with the first two rays being supernumerary. The first anal-fin pterygiophore inserts anterior to the first haemal spine situated on the $15^{\text {th }}$ vertebra. The four anterior pterygiophores comprise proximal-middle and distal radials. The remaining ptery- giophores include proximal, middle, and distal radials. The distal radials become gradually less ossified caudally, with the four or five posteriormost almost entirely cartilaginous (Fig. 9D,E). There is a well-developed flange of membrane bone along the anterior edge of the first proximal-middle radial (Fig. 9A). Smaller flanges of membrane bone are present on both the anterior and posterior margins of the proximal-middle or proximal radials of subsequent pterygiophores until the sixth. The anal-fin stay is cartilaginous in all specimens, confluent with the middle radial of the last pterygiophore (Fig. 9E). The first pterygiophore bears three unbranched anal-fin rays, the two anteriormost shorter and in a supernumerary position. The remaining 17 pterygiophores each support a single branched and serially associated anal-fin ray except for the posteriormost, which supports both a branched and a tiny unbranched ray (Fig. 9A,E). The two anteriormost branched anal-fin rays are the longest, with rays gradually becoming shorter caudally. The distal margin of the anal fin is sinuous, with the anteriormost four branched rays delimiting an anterior lobe. Bony hooks are absent from all of the anal-fin rays.

Scales. Small, thin and poorly ossified cycloid scales (Fig. 6G) are arranged in regular rows along the side and ventrolateral aspect of the body. Scales are also present along the dorsal midline anterior to the dorsal fin, but excluding the area just posterior to the occiput, which is scaleless. Scale surface features include a prominent scale focus, midway along the anterior edge of each scale, and weakly developed circuli, which are more obvious around the anterior margin than the posterior margin of each scale. There is no tubed lateral line canal (or pores).

\section{Discussion}

Tucanoichthys tucano is a miniature fish sensu Weitzman and Vari (1988). Miniature fishes typically exhibit a number of reductions and structural simplifications and Géry and Römer (1997) listed several such reductive characters in the original description of Tucanoichthys. These included a reduction in the number of pored lateral-line scales (lateral line canals and pores absent on all of the scales in our material), reduction of scales along the pre-dorsal midline, and the absence of "postorbitals" (= infraorbital bones posterior to orbit). The photograph of a cleared and stained specimen provided in the original description (Géry and Römer 1997: 68, figure 5) also shows a largely cartilaginous ethmoid region, suggesting that the bones of this region are reduced in size. Based on our detailed investigation, we established that ten bones are missing in Tucanoichthys when compared to the skeleton of a more typical, non-miniature characiform, in this case Salminus brasiliensis, which has a total of 147 bones (Mattox et al. 2014). Missing bones in Tucanoichthys include: (1) nasal (potentially present in one individual); (2) 

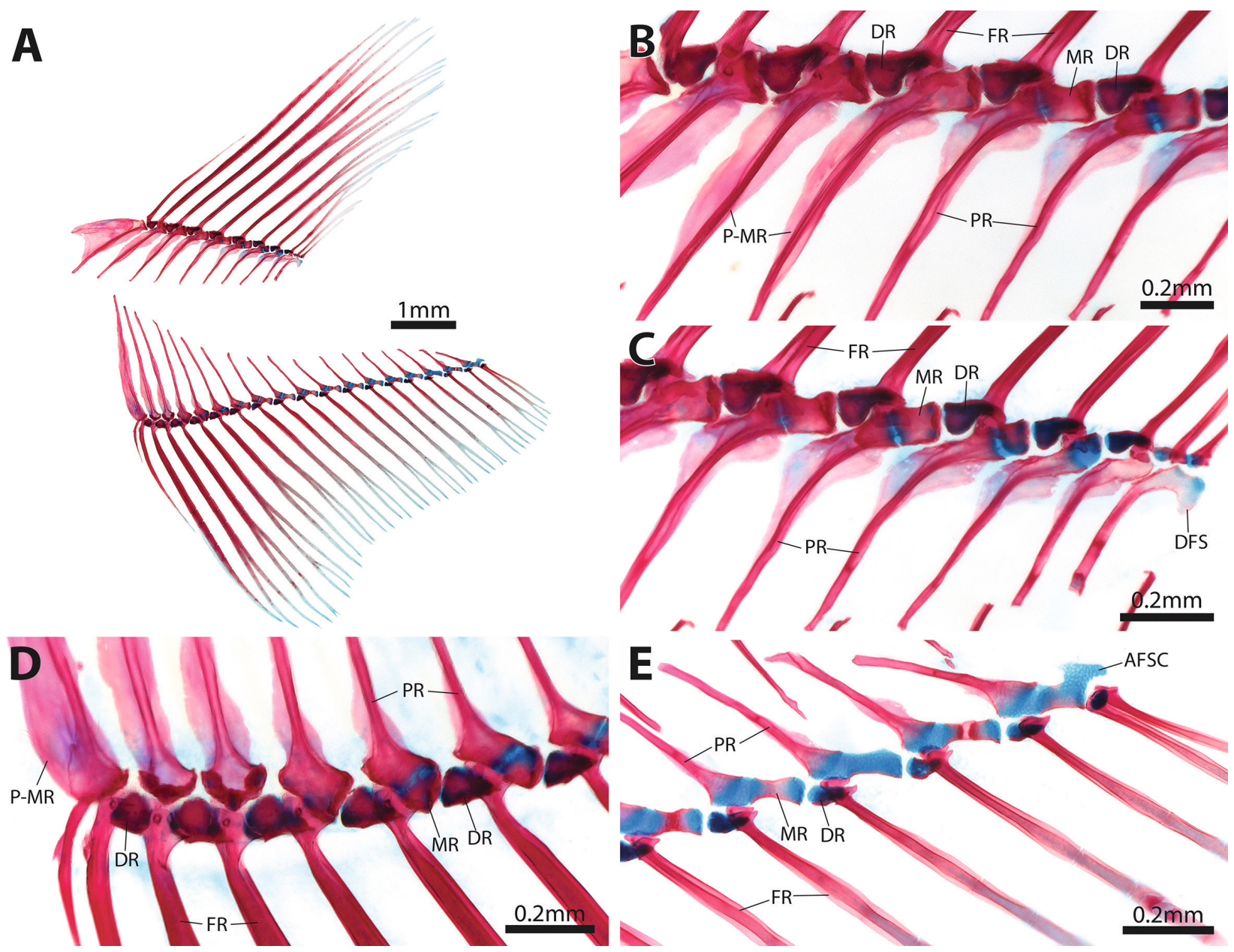

AFSC
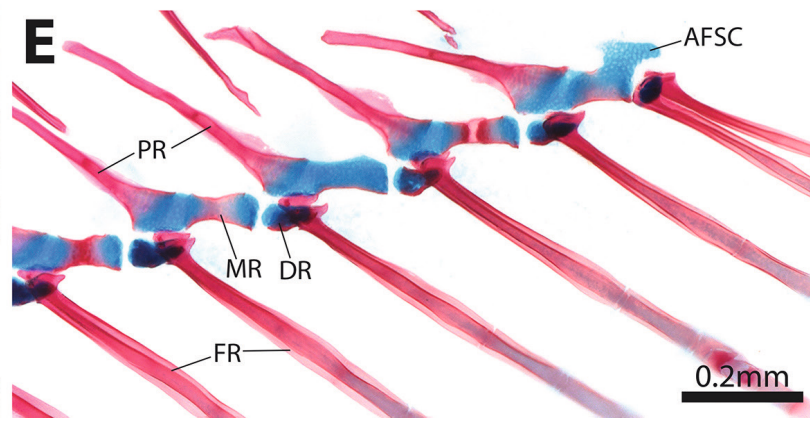

Figure 9. Tucanoichthys tucano, specimen TCWC 20316.01, $14.4 \mathrm{~mm}$ SL, c\&s. A. Dissected dorsal and anal fin and supporting skeleton, left side, lateral view. B. Base of first-sixth dorsal-fin rays showing articulation with pterygiophore elements, left side, lateral view. C. Base of fourth-eleventh dorsal-fin rays showing articulation with pterygiophore elements, left side, lateral view. D. Base of first-seventh anal-fin rays showing articulation with pterygiophore elements, left side, lateral view. E. Base of fifthteenth-twenty anal-fin rays showing articulation with pterygiophore elements, left side, lateral view. Abbreviations: AFSC, anal-fin stay cartilage; DFS, dorsal-fin stay; DR, distal radial; FR, fin ray; MR, middle radial; P-MR, proximal-middle radial; PR, proximal radial.

intercalar; (3-5) infraorbitals 4-6; (6) supraorbital; (7) claustrum; (8) extrascapular; (9) one postcleithrum; and (10) anal-fin bony stay. This represents approximately $7 \%$ of bones in the skeleton of Salminus. Priocharax Weitzman \& Vari, the most developmentally truncated characiform fish studied so far, has 17-20 bones missing (Toledo-Piza et al. 2014; Mattox et al. 2016, 2020, 2021), more than twice the number in Tucanoichthys. Although the total number of missing bones in the skeleton of Tucanoichthys is much lower than that of Priocharax, when the relative timing of appearance of these missing ossifications in a non-miniature characiform (i.e., Salminus) is taken into consideration the pattern of bone absences in Tucanoichthys provides yet another interesting example of developmental truncation in a characid fish.

All the bones missing in Tucanoichthys are those that start to develop at the final quarter of the whole developmental bone sequence of Salminus (Fig. 10), suggesting some degree of developmental truncation at the organism level. Moreover, seven of the ten missing bones are the last bones to develop when only their respective anatom- ical complexes are considered, providing evidence also of terminal deletion within each complex (Fig. 11). For example, among the missing bones in Tucanoichthys, the nasal (potentially present only in one of the six specimens that we examined) is the last bone to form in the olfactory region of the neurocranium, the missing infraorbitals 4-6 and supraorbital in Tucanoichthys are the last four bones to develop in the infraorbital series in Salminus, the claustrum is the last of the Weberian ossicles to appear in the Weberian apparatus, and the anal-fin stay is the last ossification to develop in the anal-fin skeleton. In addition, the missing extrascapular in Tucanoichthys is the second-to-last bone to develop in the pectoral girdle of Salminus.

Some of the missing bones in Tucanoichthys are also lacking in other miniature characiforms, such as the nasal in the alestid Lepidarchus adonis Roberts (Roberts 1966: 210), the characid Hyphessobrycon elachys Weitzman (Mirande 2010: 400), and all members of the characid genus Priocharax (Mattox et al. 2016). The nasal is also missing in the small characid Coptobrycon bilineatus 


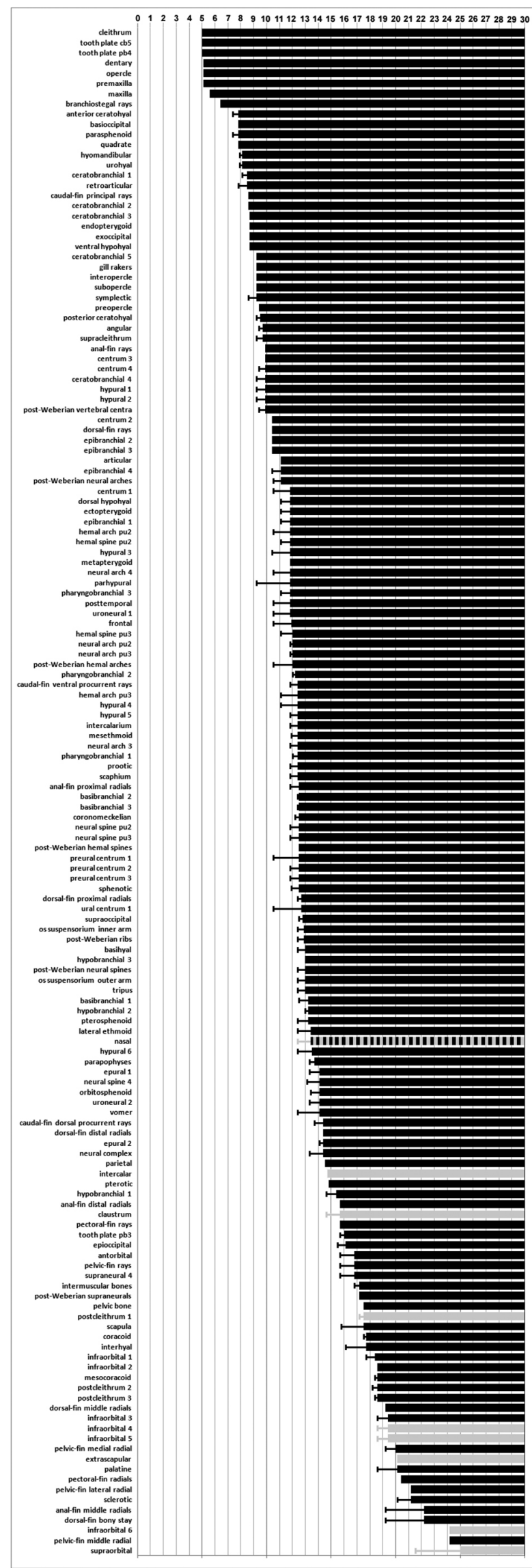

Figure 10. Diagram to illustrate relation between whole sequence of ossification of Salminus brasiliensis (from Mattox et al. 2014) and losses in the skeleton of Tucanoichthys tucano. Solid horizontal bars represent bone presence (fixed length). Error bars associated with solid horizontal bars indicate length at which a particular bone is present in some but not all individuals (minimum length). Black bars represent ossifications present and gray bars ossifications absent in Tucanoichthys. The black/grey bar represents the nasal in which intraspecific variation was found. 


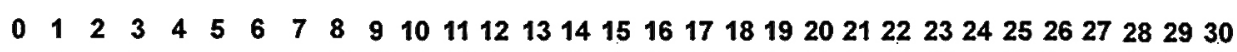

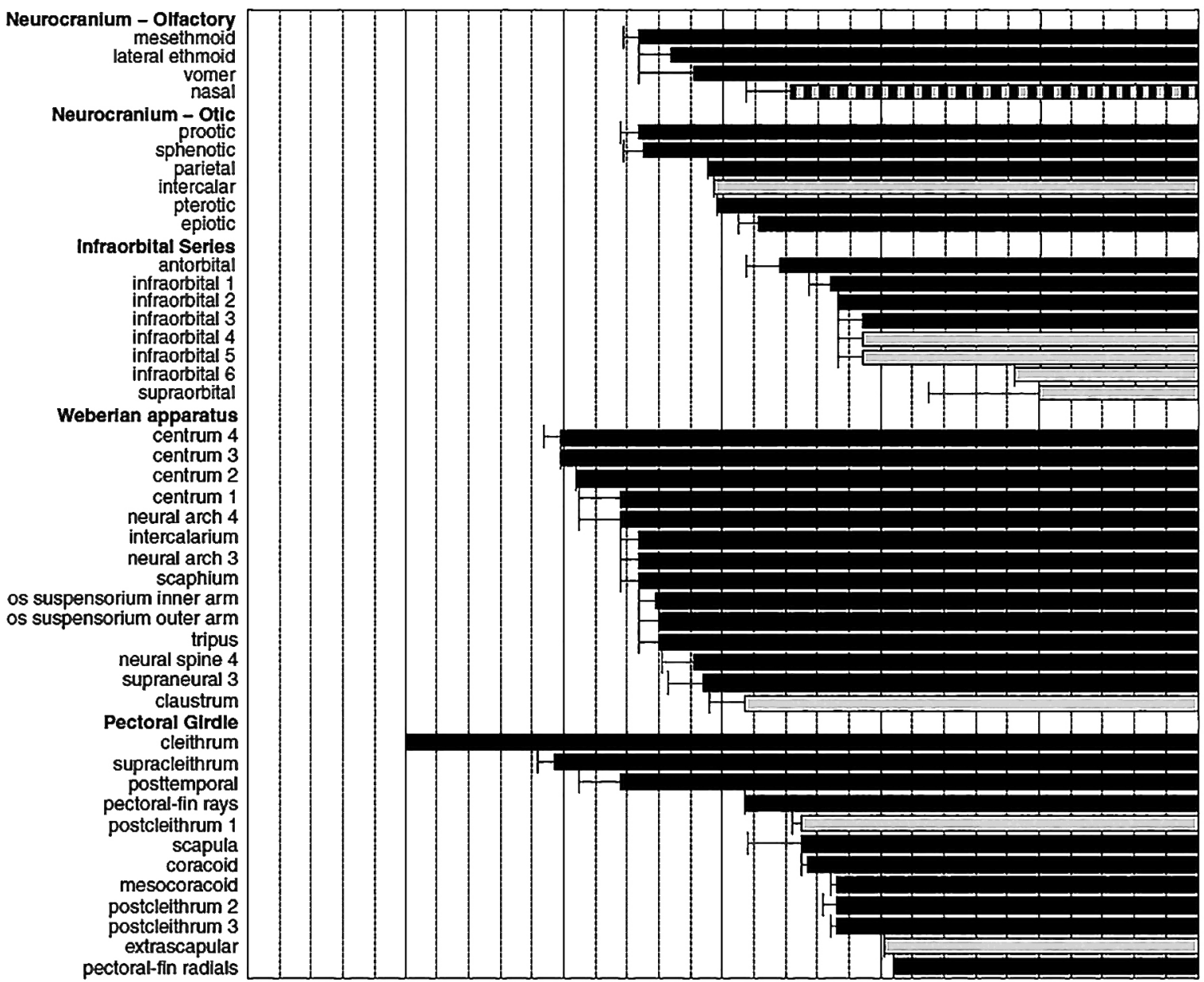

Figure 11. Diagram of selected anatomical complexes showing relation between sequence of ossification of Salminus brasiliensis (from Mattox et al. 2014) and losses in the skeleton of Tucanoichthys tucano. Solid horizontal bars represent bone presence (fixed length). Error bars associated with solid horizontal bars indicate length at which a particular bone is present in some but not all individuals (minimum length). Black bars represent ossifications present and gray bars ossifications absent in Tucanoichthys. The black/grey bar represents the nasal in which intraspecific variation was found.

(Ellis) (Langeani and Serra 2010), and its widespread absence has been considered previously to be a product of convergent loss in some of the aforementioned genera (Mattox et al. 2016). Along similar lines, loss of the extrascapular has likely also occurred independently in multiple lineages of miniature characids, including for example Iotabrycon Roberts (Roberts 1973), Tyttocharax Fowler and Xenurobrycon Myers and Miranda-Ribeiro (Weitzman and Fink 1985), and Priocharax (Mattox et al. 2016). On the other hand, a striking and unusual reduction in the skeleton of Tucanoichthys is the loss of the claustrum in the Weberian apparatus and Priocharax, to the best of our knowledge, is the only other characiform that lacks this Weberian ossicle (Weitzman and Vari 1987; Mattox et al. 2016, 2020, 2021).

Many small characiforms have reductions in the infraorbital series, and the lack of the supraorbital has been interpreted either as a synapomorphy of a large clade within the Characidae (e.g., Malabarba and Weitzman 2003) or as a synapomorphy of the Characidae when some taxa traditionally assigned to this family are removed and assigned family-level status (e.g., Oliveira et al. 2011). Further reduction in the infraorbital series is usually restricted to one or two missing infraorbitals of those that appear late in the ontogeny of Salminus (Mattox et al. 2014), infraorbital 4 and/or 6 (e.g., Weitzman 1954; Vari 1979, 1989; Weitzman and Fink 1983; Weitzman and Malabarba 1999; Zanata and Vari 2005; Langeani and Serra 2010; Mirande 2010, 2019; Mattox and Toledo-Piza 2012). Extreme reduction in the infraorbital series is rare and includes loss of infraorbitals $4-6$ as described here and already reported for miniature characids belonging to other genera such as Iotabrycon (Roberts 1973), Paracheirodon Géry (Weitzman and Fink 1983), Spintherobolus Eigenmann (Weitzman and Malabarba 1999), Amazonspinther Bührnheim, Carvalho, Malabarba and Weitzman (Bührnheim et al. 2008), Trochilocharax Zarske (Zarske 2010), Tyttobrycon (Marinho et al. 2013; Abrahão et al. 2019) and Priocharax (Mattox et al. 2016). Most species of the latter genus actually lack infraorbitals in their entirety (Weitzman and Vari 1987; Toledo-Piza et al. 2014; Mattox et al. 2020). 
The number of postcleithra in Tucanoichthys is also reduced and worth a comment here. Most characiforms have three vertically aligned postcleithra, with the dorsalmost (=postcleithrum 1) and middle (=postcleithrum 2 ) of an elliptical shape, and the ventralmost (=postcleithrum 3) rod-like and often with a round posterodorsal lamella (e.g., see Weitzman 1962; Mattox and Toledo-Piza 2012). Tucanoichthys has only two postcleithra, including a more dorsally located elliptical postcleithrum and a ventral rod-shaped postcleithrum. The identity of the dorsal postcleithrum in Tucanoichthys is ambiguous because it could be homologous to either postcleithrum 1 or 2 of other characiforms as it partially matches the topology of both. Toledo-Piza et al. (2014) discussed the issue of postcleithra homology in miniature characids in detail and mentioned that in taxa with only two postcleithra, these represent either postcleithra 1 and 2, or postcleithra 2 and 3. This led Toledo-Piza et al. (2014) to interpret the two postcleithra in Priocharax nanus Toledo-Piza, Mattox and Britz as postcleithra 2 and 3, based on the shape of the ventralmost element (=postcleithrum 3 ) and on the fact that these bones are always juxtaposed dorsoventrally. Within Priocharax, there is variation in the number of postcleithra, with species lacking all three (Weitzman and Vari 1987), species with only a single elliptical postcleithrum (Mattox et al. 2016), and species with postcleithra 2 and 3 (Toledo-Piza et al. 2014; Mattox et al. 2020, 2021). Following the rationale of Toledo-Piza et al. (2014) we here interpret the postcleithra in Tucanoichthys as postcleithra 2 and 3. Other miniature characiforms with the same postcleithrum pattern include the characid Iotabrycon (Roberts 1973) and some species of the Crenuchidae, including Elachocharax Myers, Microcharacidium Buckup and Odontocharacidium Buckup (Buckup 1993).

In addition to the aforementioned bone absences, Tucanoichthys is also characterized by several skeletal simplifications commonly attributed to processes of heterochrony (Myers 1958; Roberts 1973; Weitzman and Fink 1983; Britz and Conway 2009; Britz et al. 2009; Mattox et al. 2016). This includes the complete absence of the lateral line canal on body scales, and the absence of most components of the cephalic lateral line sensory canals on the skull and pectoral girdle, with a rudimentary canal (i.e., open, unroofed by bone) present only on the preopercle. Another reductive character of Tucanoichthys is the absence or reduced size of the lateral arm of the epiotic (=epioccipital bridge sensu Weitzman and Fink 1983: 354), a bony projection of the epiotic that bisects the posttemporal fossa in most characiforms (e.g., see Weitzman 1962: Figs 3 and 5). Complete absence of the lateral arm of the epiotic has been recorded previously for several miniature characids, including Iotabrycon (Roberts 1973), Paracheirodon, Tyttocharax and Xenurobrycon (Weitzman and Fink 1983, 1985), Hasemania (Mirande 2010), Cyanogaster (Mattox et al. 2013) and Priocharax (Mattox et al. 2016), in addition to other small characiforms such as the miniature crenuchid Odontocharacidium aphanes (Weitzman \& Kanazawa) (Weitzman and Fink 1983) and the lebiasinid Pyrrhulina australis Eigen- mann \& Kennedy (Mirande 2010). The lateral arm of the epiotic is the last part of this bone to develop in Salminus (Mattox et al. 2014) and its absence or reduced size in $\mathrm{Tu}$ canoichthys is another case of developmental truncation at the character level.

The shape of the opercle in Tucanoichthys offers another possible example of developmental truncation at the character level. In most characiforms, the opercle is an elliptical bone that completely covers the branchial chamber laterally (e.g., Weitzman 1962). The opercle is slightly concave medially where the adductor operculi inserts above the bony strut that extends posteriorly from the opercular condyle. Tucanoichthys, in contrast, has an opercle that does not fully cover the branchial cavity as it leaves the portion above the strut almost without bony cover. This results in the partial exposure of the branchial chamber, which is visible in lateral view. To the best of our knowledge, the only other characid to share a similar condition is Priocharax (Mattox et al. 2016). The development of the opercle in Salminus begins early in ontogeny as a thin splint of bone extending posteriorly from the opercular condyle. During development, the bony splint increases in size to become the medial strut of the opercle, and soon develops a ventral lamellar expansion of the strut, and subsequently a dorsal expansion (Mattox et al. 2014). The adult condition in Tucanoichthys and Priocharax thus resembles that of a juvenile Salminus and is therefore regarded as another example in both genera of truncation at the character level.

Contrary to the description in Géry and Römer (1997), Tucanoichthys has a well-developed pseudotympanum, characterized by two triangular openings in the musculature of the humeral region almost entirely separated from each other by a bundle of the obliquus superioris of the hypaxial musculature attached to the rib of the fifth vertebra (Fig. 12A). The anterior aperture is anterior to the fifth rib and the posterior aperture is anterior to the sixth rib. A similar condition of the pseudotympanum has been reported in Spintherobolus (Weitzman and Malabarba 1999), Amazonspinther (Bührnheim et al. 2008), in some species of Tyttobrycon (Marinho et al. 2013; Abrahão et al. 2019) in addition to Axelrodia sp., Hyphessobrycon elachys and Paracheirodon axelrodi (Schultz) (Malabarba 1998; Marinho et al. 2013). Although Malabarba (1998) described a similar organization for the pseudotympanum in Atopomesus pachyodus Myers, there is a notable size difference between the two apertures in this species (i.e., anterior aperture diminutive in comparison to the posterior; Fig. 12B) which is different from the condition in Tucanoichthys and the other species listed above. We consider the condition in Atopomesus to be similar to that of most members of the Characinae (Malabarba 1998; Mattox and Toledo-Piza 2012) in which there is a single large triangular aperture anterior to the sixth rib with the anterior tip of the triangle slightly extending over the region anterior to the fifth rib.

In the original description of Tucanoichthys, Géry and Römer (1997) compared it with a number of other miniature characids since the shape of its jaws and presence 


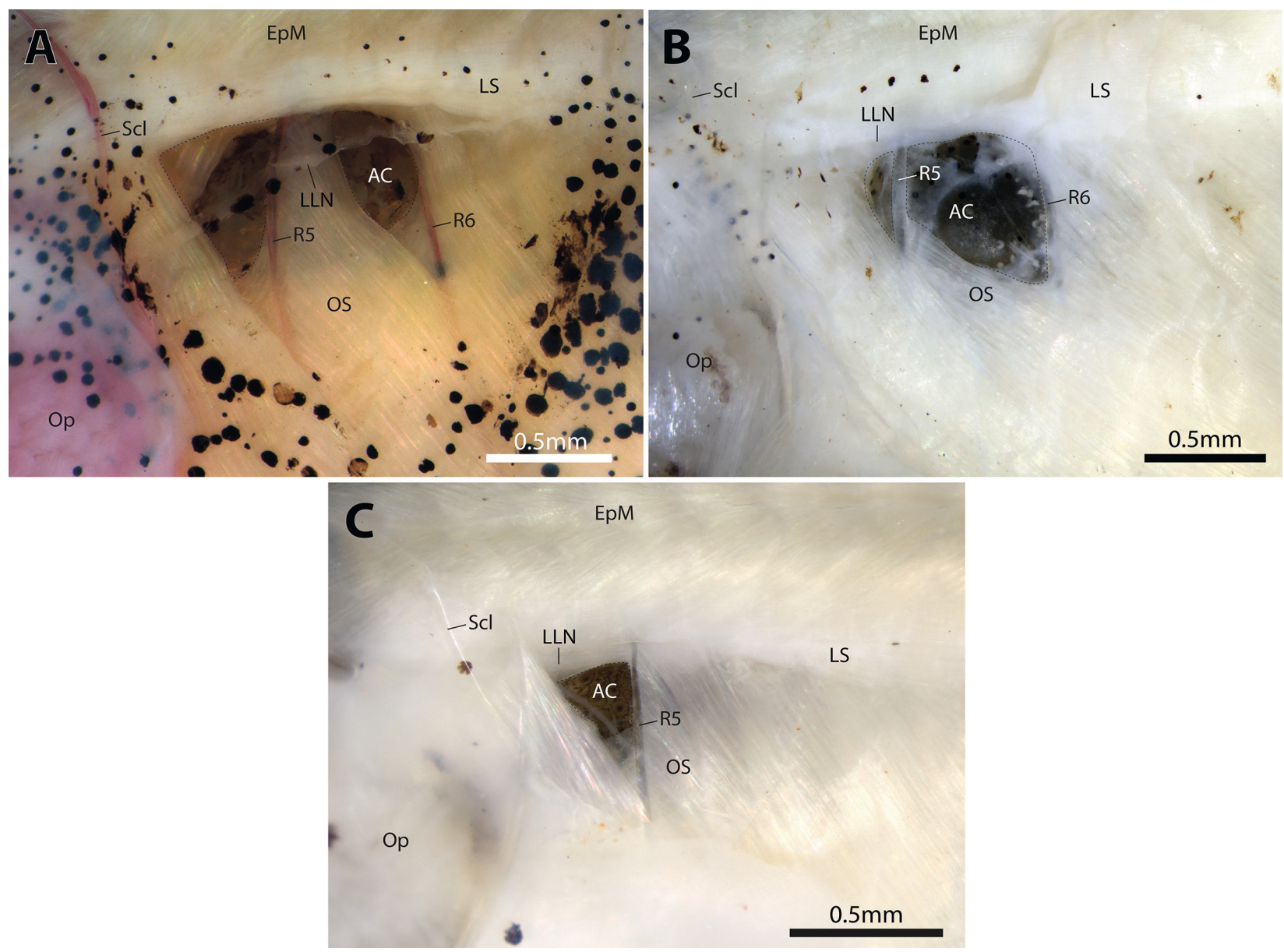

Figure 12. A. Right side pseudotympanum of Tucanoichthys tucano (image reversed), specimen TCWC 20316.02, $15.5 \mathrm{~mm}$ SL. B. Left side pseudotympanum of Atopomesus pachyodus, specimen LBP 23871, $23.2 \mathrm{~mm} \mathrm{SL}$. C. Left side pseudotympanum of Priocharax varii, specimen MZUSP 125787, paratype, $13.5 \mathrm{~mm}$ SL. Skin removed from side of body to reveal pseudotympanum. Specimen in A was photographed after 1 day in solution of 70\% ETOH to which a small amount of alizarin red S was added. Abbreviations: AC, anterior chamber of swimbladder; EpM, epaxial musculature; LLN, lateral line nerve; LS, lateralis superficialis; Op, opercle; OS, obliquus inferioris; R5-6, rib 5-6; Scl, supracleithrum.

of a strictly conical dentition did not suggest a putative close relationship with miniature lebiasinids and crenuchids. Géry and Römer (1997) also ruled out members of the "Tetragonopterinae" and Glandulocaudinae as close relatives of Tucanoichthys because of the multicuspid dentition of tetragonopterines and the absence in Tucanoichthys of the elaborate caudal organ typical of glandulocaudines. Instead, Géry and Römer (1997) focused their comparisons on members of the "Aphyoditeinae" and on Priocharax, taxa that share with Tucanoichthys a small-body size, a strictly conical dentition, and an incomplete system of lateral line canals. In reference to the aphyoditeines, Géry and Römer (1997) pointed out many differences in jaw structure and dentition between its members and Tucanoichthys. Based on their observations, Géry and Römer (1997) refrained from assigning Tucanoichthys to any of the subfamilies of Characidae recognized at that time but hypothesized that the relationships of Tucanoichthys may be among genera that were then considered as incertae sedis in Characidae, such as Priocharax, Acanthocharax Eigenmann, Gnathocharax Fowler, Heterocharax Eigenmann, Hoplocharax Géry and Lonchogenys Myers.
Acanthocharax is now included in the Characinae (e.g., Lucena 1998; Lucena and Menezes 2003; Mattox and Toledo-Piza 2012) and is morphologically very different from Tucanoichthys. Gnathocharax, Heterocharax, Hoplocharax and Lonchogenys were recently grouped together in the Heterocharacinae along with Gilbertolus Eigenmann and Roestes Günther based on the presence and structure of their pseudotympani and a number of derived osteological characters (see Mattox and Toledo-Piza 2012: 889). Tucanoichthys lacks the spiniform process on the preopercle typical of the Heterocharacinae and the structure of the pseudotympanum of Tucanoichthys is different from the one found in this subfamily (compare Figs. 12A and 12C). However, the shape of the orbitosphenoid and of the inner arm of the os suspensorium resemble that of heterocharacins. Tucanoichthys also shares with the members of the Heterocharacinae a fully toothed maxilla with strictly conical teeth, a feature not common among characids and related groups. Moreover, the small sized genera of the Heterocharacinae (Gnathocharax, Heterocharax, Hoplocharax and Lonchogenys) were grouped together in the tribe Heterocharacini based on seven unambiguous synapomorphies (Mattox \& To- 
ledo-Piza 2012), three of which are reductive characters and are also shared with Tucanoichthys: absence of a spiniform projection on the pterotic, absence of a suprapreopercle, and a cartilaginous anal-fin stay.

Priocharax, a genus of miniature fishes that has been assigned to the Characinae in the past (e.g., Lucena 1998; Lucena and Menezes 2003), was tentatively included in the Heterocharacinae by Mattox and Toledo-Piza (2012) based on the structure of the pseudotympanum, the form of the inner arm of the os suspensorium and the aforementioned reductive features shared with the Heterocharacini. However, as Priocharax has a skeleton that is highly truncated for a characiform, it took a few years to gather additional evidence that supports its close relationship to heterocharacines based on the reinterpretation of some of its reductive features as derived and developmentally truncated (Mattox et al. 2016). One of the highly unusual truncations in Priocharax (all species excluding $P$. nanus) is the absence of the claustrum, a feature not known in any other characiform until recently. It is noteworthy that Tucanoichthys is the only other characiform to also lack the claustrum. Additional reductive features shared between Tucanoichthys and Priocharax include the predominantly cartilaginous ethmoid region, the absence or reduction of the lateral arm of the epiotic, the lack of the dorsal expansion of the opercle, the absence of infraorbitals 4-6, the absence of postcleithrum 1 , and a large gap between neural arches 3 and 4 . Notably, the two genera also share a number of other non-reductive (progressive) characters, including the structure of the jaws, a strictly conical dentition, a fully toothed maxilla, and the form of the os suspensorium.

A recent molecular phylogenetic study including $T u$ canoichthys tucano and over 290 other characoid taxa recovered T. tucano as a member of the Stethaprioninae (Melo et al. 2021). Within this large clade, T. tucano was placed in a sister group relationship with another miniature species, Tyttobrycon cf. xeruini (Melo et al. 2021). Both taxa share the reduction in the number of infraorbital bones (e.g., Marinho et al. 2013; Abrahão et al. 2019), but the shape of the jaws and teeth are quite different from each other as already pointed out by Géry and Römer (1997). The structure of the pseudotympanum of Tucanoichthys and Ty. xeruini is also different. In Tyttobrycon xeruini, there is a small triangular aperture anterior to the fifth rib (Marinho et al. 2013), a condition similar to that in heterocharacines including Priocharax (Fig. 12C; Mattox and Toledo-Piza 2012). Three other species of Tyttobrycon, however, have the pattern found in Tucanoichthys (Marinho et al. 2013; Abrahão et al. 2019). A complete osteological survey of Tyttobrycon has yet to be conducted and would be needed to better understand its skeletal features in comparison with those of Tucanoichthys.

A dedicated phylogenetic study of the shared characters of Tucanoichthys, Tyttobrycon, and Priocharax is beyond the scope of the present study but we expect that such an investigation will shed light on the relationships of the enigmatic Tucanoichthys and its putative placement with Priocharax or Tyttobrycon.

\section{Acknowledgements}

This study was conducted at Departamento de Biologia, UFSCar - Universidade Federal de São Carlos (UFSCar) and Department of Ecology and Conservation Biology, Texas A\&M University (TAMU), which provided space and access to facilities. The authors are thankful to $\mathrm{C}$. Oliveira (Departamento de Biologia Estrutural e Funcional, Instituto de Biociências, Universidade Estadual Paulista - campus Botucatu) for the loan of part of the examined specimens. R. Britz kindly gave valuable suggestions to a previous version of the manuscript. F. Schäfer (Aquarium Glaser $\mathrm{GmbH}$ ) generously provided the photographs of live specimens of Tucanoichthys used in Figure 1. This research resulted from an international collaboration sponsored by FAPESP SPRINT/UFSCar (FAPESP Proc. 2018/22592-0) and TAMU (TAMU/FAPESP Proc. 2018-3-16). GMTM acknowledges financial support from FAPESP (Proc. 2017/01970-4). KWC acknowledges financial support from TAMU Agrilife Research (HATCH TEX09452). This is publication number 1653 of the TAMU Biodiversity Research and Teaching Collections and publication number 05 of the TAMU Aquarium Research Facility.

\section{References}

Abrahão VP, Pastana M, Marinho MMF (2019) On a remarkable sexual dimorphic trait in the Characiformes related to the olfactory organ and description of a new miniature species of Tyttobrycon Géry (Characiformes: Characidae). PLoS ONE 14(12): e0226130. https:// doi.org/10.1371/journal.pone.0226130

Arratia G, Schultze H-P (1991) Palatoquadrate and its ossifications: development and homology within osteichthyans. Journal of Morphology 208: 1-81.

Britz R, Conway KW (2009) Osteology of Paedocypris, a miniature and highly developmentally truncated fish (Teleostei: Ostariophysi: Cyprinidae). Journal of Morphology 270: 389-412. https://doi. org/10.1002/jmor. 10698

Britz R, Conway KW (2016) Danionella dracula, an escape from the cypriniform Bauplan via developmental truncation? Journal of Morphology 277: 147-166. https://doi.org/10.1002/jmor.20486

Britz R, Conway KW, Rüber L (2009) Spectacular morphological novelty in a miniature cyprinid fish, Danionella dracula, n. sp. Proceedings of the Royal Society B 276: 2179-2186. https://doi. org/10.1098/rspb.2009.0141

Britz R, Conway KW, Rüber L (2014) Miniatures, morphology and molecules: Paedocypris and its phylogenetic position (Teleostei, Cypriniformes). Zoological Journal of the Linnean Society 172: 556-615. https://doi.org/10.1111/zoj.12184

Buckup PA (1993) Phylogenetic interrelationships and reductive evolution in Neotropical characidiin fishes (Characiformes, Ostariophysi). Cladistics 9: 305-341.

Bührnheim CM, Carvalho TP, Malabarba LR, Weitzman SH (2008) A new genus and species of characid fish from the Amazon basin: the recognition of a relictual lineage of characid fishes (Ostariophysi: Cheirodontinae: Cheirodontini). Neotropical Ichthyology 6: 663678. https://doi.org/10.1590/S1679-62252008000400016

Caires RA, Toledo-Piza M (2018) A new species of miniature fish of the genus Microphillypnus (Gobioidei: Eleotridae) from the upper Rio Negro basin, Amazonas, Brazil. Copeia 106: 49-55. https://doi. org/10.1643/CI-17-634 
Calegari BB, Reis, RE (2017) New species of the miniature genus Gelanoglanis (Siluriformes: Auchenipteridae) from the Tocantins River basin (Brazil) and osteological description of G. nanonoctilocus. Journal of Fish Biology 90: 1702-1716. http://doi:10.1111/ jfb. 13181

Camelier P, Dagosta FCP, Marinho MMF (2018) New remarkable sexually dimorphic miniature species of Hyphessobrycon (Characiformes: Characidae) from the upper Rio Tapajós basin. Journal of Fish Biology 92: 1149-1162. https://doi:10.1111/jfb.13579

Carvalho TP, Lundberg JG, Baskin JN, Friel JP, Reis RE (2016) A new species of the blind and miniature genus Micromyzon Friel and Lundberg, 1996 (Siluriformes: Aspredinidae) from the Orinoco River: describing catfish diversity using high-resolution computed tomography. Proceedings of the Academy of Natural Sciences of Philadelphia 165: 37-53. http://dx.doi.org/10.1635/053.165.0104

Carvalho TP, Reis RE, Friel JP (2017) A new species of Hoplomyzon (Siluriformes: Aspredinidae) from Maracaibo Basin, Venezuela: osteological description using high-resolution computed tomography of a miniature species. Neotropical Ichthyology 15: e160143. https://doi.org/10.1590/1982-0224-20160143

Conway KW, Kubicek KM, Britz R (2017) Morphological novelty and modest developmental truncation in Barboides, Africa's smallest vertebrates (Teleostei: Cyprinidae). Journal of Morphology 278(6): 750-767. https://doi.org/10.1002/jmor.20670

Costa WJEM, Katz AM, Mattox JLO, Rangel-Pereira FS (2019) Two new species of miniature psammophilic sarcoglanidine catfishes of the genus Microcambeva from the Atlantic Forest of eastern Brazil (Siluriformes: Trichomycteridae). Journal of Natural History 53: 1837-1851. https://doi.org/10.1080/00222933.2019.1669729

Fink SV, Fink WL (1981) Interrelationships of the ostariophysans fishes (Teleostei). Zoological Journal of the Linnean Society 72: 297-353.

Géry J, Römer U (1997) Tucanoichthys tucano gen. n. sp. n., a new miniature characid fish (Teleostei: Characiformes: Characidae) from the Rio Uaupes basin in Brazil. Aqua, Journal of Ichthyology and Aquatic Biology 2: 65-72.

Gould SJ (1971) Geometric similarity in allometric growth: a contribution to the problem of scaling in the evolution of size. American Naturalist 105: 113-136.

Henschel E (2016) A new catfish species of the Trichomycterus hasemani group (Siluriformes: Trichomycteridae), from the Branco river basin, northern Brazil. Vertebrate Zoology 66: 117-123.

Henschel E, Bragança PHN, Rangel-Pereira F, Costa WJEM (2020a) A new psammophilic species of the genus Ammoglanis (Siluriformes, Trichomycteridae) from the Amazon River basin, northern Brazil. Zoosystematics and Evolution 96: 67-72. https://doi.org/10.3897/ zse. 96.48952

Henschel E, Lujan NK, Baskin JN (2020b) Ammoglanis natgeorum, a new miniature pencil catfish (Siluriformes: Trichomycteridae) from the lower Atabapo River, Amazonas, Venezuela. Journal of Fish Biology 2020: 1-10. https://doi.org/10.1111/jfb. 14515

Jerep FC, Dagosta FCP, Ohara WM (2018) A new miniature species of Serrapinnus (Characiformes: Characidae) from the upper Rio Araguaia, Brazil. Copeia 106: 180-187. https://doi.org/10.1643/CI$17-653$

Johnson DG, Brothers EB (1993) Schindleria: a paedomorphic goby (Teleostei: Gobioidei). Bulletin of Marine Science 52: 441-471.

Langeani F, Serra JP (2010) Coptobrycon bilineatus (Ellis, 1911) (Characiformes: Characidae): redescription and comments on its phylogenetic relationships. Neotropical Ichthyology 8: 727-736. https://doi.org/10.1590/S1679-62252010000400004
Lima FCT, Malabarba LR, Buckup PA, da Silva JFP, Vari RP, Harold A, Benine R, Oyakawa OT, Pavanelli CS, Menezes NA, Lucena CAS, Malabarba MCSL, Lucena ZMS, Reis RE, Langeani F, Casatti L, Bertaco VA, Moreira C, Lucinda PHF (2003) Genera incertae sedis in Characidae. In: Reis RE, Kullander SO, Ferraris Jr. CJ (Eds) Check list of the freshwater fishes of South and Central America. Edipucrs, Porto Alegre, 106-169.

Lima FCT, Caires RA, Conde-Saldaña CC, Mirande JM, Carvalho FR (2021) A new miniature Pristella (Actinopterygii: Characiformes: Characidae) with reversed sexual dimorphism from the rio Tocantins and rio São Francisco basins, Brazil. Canadian Journal of Zoology 99: 339-348. https://dx.doi.org/10.1139/cjz-2020-0241

Malabarba LR (1998) Monophyly of the Cheirodontinae, characters and major clades (Ostariophysi: Characidae). In: Malabarba LR, Reis RE, Vari RP, Lucena ZMS, Lucena CAS (Eds) Phylogeny and classification of Neotropical fishes. Edipucrs, Porto Alegre, 193-233.

Malabarba LR, Weitzman SH (2003) Description of a new genus with six new species from Southern Brazil, Uruguay and Argentina, with a discussion of a putative characid clade (Teleostei: Characiformes: Characidae). Comunicações do Museu de Ciências e Tecnologia da PUCRS, série Zoologia 16: 67-151.

Marinho MMF, Bastos DA, Menezes NA (2013) New species of miniature fish from Marajó Island, Pará, Brazil, with comments on its relationships (Characiformes: Characidae). Neotropical Ichthyology 11: 739-746. https://doi.org/10.1590/S1679-62252013000400002

Mattox GMT, Toledo-Piza M (2012) Phylogenetic study of the Characinae (Teleostei: Characiformes: Characidae). Zoological Journal of the Linnean Society 165: 809-915. https://doi.org/10.1111/j.10963642.2012.00830.x

Mattox GMT, Britz R, Toledo-Piza M, Marinho MMF (2013) Cyanogaster noctivaga, a remarkable new genus and species of miniature fish from the Rio Negro, Amazon basin (Ostariophysi: Characidae). Ichthyological Exploration of Freshwaters 23: 297-318.

Mattox GMT, Britz R, Toledo-Piza M (2014) Skeletal development and ossification sequence of the characiform Salminus brasiliensis (Teleostei: Ostariophysi: Characidae). Ichthyological Exploration of Freshwaters 25: 103-158.

Mattox GMT, Britz R, Toledo-Piza M. (2016) Osteology of Priocharax and remarkable developmental truncation in a miniature Amazonian fish (Teleostei: Characiformes: Characidae). Journal of Morphology 277: 65-85. https://doi.org/10.1002/jmor.20477

Mattox GMT, Souza CS, Toledo-Piza M, Britz R, Oliveira C (2020) A new miniature species of Priocharax (Teleostei: Characiformes: Characidae) from the Rio Madeira drainage, Brazil, with comments on the adipose fin in characiforms. Vertebrate Zoology 70(3): 417433. http://dx.doi.org/10.26049/VZ70-3-2020-11

Mattox GMT, Souza CS, Toledo-Piza M, Oliveira C (2021) A new miniature species of Priocharax (Characiformes: Characidae) from the upper rio Ipixuna, Purus drainage, Brazil. Neotropical Ichthyology 19(2): e21004. https://doi.org/10.1590/1982-0224-2021-0048

Melo BF, Sidlauskas BL, Near TJ, Roxo FF, Ghezelayagh A, Ochoa LE, Stiassny MLJ, Arroyave J, Chang J, Faircloth BC, MacGuigan DJ, Harrington RC, Benine RC, Burns MD, Hoekzema K, Sanches NC, Maldonado-Ocampo JA, Castro RMC, Foresti F, Alfaro ME, Oliveira C (2021) Accelerated diversification explains the exceptional species richness of tropical characoid fishes. Systematic Biology syab040. https://doi.org/10.1093/sysbio/syab040

Mendonça MB, Peixoto LAW, Dutra GM, Netto-Ferreira AL (2016) A new miniature of Xenurobryconini (Characiformes: Characidae) 
from the rio Tapajós basin, Brazil. Neotropical Ichthyology 14: e150057. https://doi.org/10.1590/1982-0224-20150057

Mirande JM (2010) Phylogeny of the family Characidae (Teleostei: Characiformes): from characters to taxonomy. Neotropical Ichthyology 8: 385-568. https://doi.org/10.1590/S1679-62252010000300001

Mirande JM (2018) Morphology, molecules and the phylogeny of Characidae (Teleostei, Characiformes). Cladistics 2018: 1-19. https:// doi.org/10.1111/cla. 12345

Myers GS (1958) Trends in the evolution of teleostean fishes. Stanford Ichthyological Bulletin 7: 27-30.

Ohara WM, Jerep FC, Cavallaro MR (2019) A new species of Microschemobrycon (Characiformes: Characidae) from Rio Xingu basin, Brazil. Zootaxa 4576: 326-336. https://doi.org/10.11646/zootaxa.4576.2.6

Oliveira C, Avelino GS, Abe KT, Mariguela TC, Benine RC, Ortí G, Vari RP, Castro, RMC (2011) Phylogenetic relationships within the speciose family Characidae (Teleostei: Ostariophysi: Characiformes) based on multilocus analysis and extensive ingroup sampling. BMC Evolutionary Biology 11: 1-25. https://doi.org/10.1186/1471-2148$11-275$

Pastana MNL, Dagosta FCP, Esguícero ALH (2017) A new sexually dichromatic miniature Hyphessobrycon (Teleostei: Characiformes: Characidae) from the Rio Formiga, upper Rio Juruena basin, Mato Grosso, Brazil, with a review of sexual dichromatism in Characiformes. Journal of Fish Biology 91: 1301-1318. https://doi.org/ $10.1111 / \mathrm{jfb} .13449$

Roberts TR (1966) Description and osteology of Lepidarchus adonis, a remarkable new characid fish from West Africa. Stanford Ichthyological Bulletin 8: 209-227.

Roberts TR (1973) The glandulocaudine characid fishes of the Guayas Basin in western Ecuador. Bulletin of the Museum of Comparative Zoology 144: 489-514.

Rüber L, Kottelat M, Tan HH, Ng PKL, Britz R (2007) Evolution of miniaturization and the phylogenetic position of Paedocypris, comprising the world's smallest vertebrate. BMC Evolutionary Biology 7: 38. https://doi.org/10.1186/1471-2148-7-38

Schaefer SA, Weitzman SH, Britski HA (1989) Review of the Neotropical catfish genus Scoloplax (Pisces: Loricarioidea: Scoloplacidae) with comments on reductive characters in phylogenetic analysis. Proceedings of the Academy of Natural Sciences of Philadelphia 141: 181-211.

Taylor WR, van Dyke GC (1985) Revised procedures for staining and clearing small fishes and other vertebrates for bone and cartilage study. Cybium 9: 107-119.

Toledo-Piza M, Mattox GMT, Britz R (2014) Priocharax nanus, a new miniature characid from the Rio Negro, Amazon basin (Ostariophysi: Characiformes), with an updated list of Neotropical freshwater miniature fishes. Neotropical Ichthyology 12: 229-246. http:// dx.doi.org/10.1590/1982-0224-20130171

Valdesalici S, Nielsen DTB (2017) Laimosemion gili (Teleostei: Cyprinodontiformes: Cynolebiidae), a new miniature species from the Rio Negro basin, Brazil. aqua, International Journal of Ichthyology 23: $97-102$
Van der Sleen P, Lima FCT (2018) Family Characidae incertae sedis including subfamilies Tetragonopterinae and Stethaprioninae. In: van der Sleen P, Alberts JS (Eds) Field guide to the fishes of the Amazon, Orinoco \& Guianas. Princeton University Press, Princeton, New Jersey, 128-140.

Vari RP (1979) Anatomy, relationships and classification of the families Citharinidae and Distichodontidae (Pisces, Characoidea). Bulletin of the British Museum (Natural History) 36: 261-344.

Vari RP (1989) A phylogenetic study of the Neotropical characiform family Curimatidae (Pisces: Ostariophysi). Smithsonian Contributions to Zoology 471: 1-71.

Vieira LS, Netto-Ferreira AL (2021) A new species of Microcharacidium (Characiformes: Crenuchidae) from the Central Amazon, Brazil. Canadian Journal of Zoology 99: 57-61. https://dx.doi.org/10.1139/ cjz-2020-0138

Weitzman SH (1954) The osteology and the relationships of the south american characid fishes of the subfamily Gasteropelecinae. Stanford Ichthyological Bulletin 4: 213-263.

Weitzman SH (1962) The osteology of Brycon meeki, a generalized characid fish, with an osteological definition of the family. Stanford Ichthyological Bulletin 8: 1-77.

Weitzman SH (1974) Osteology and evolutionary relationships of the Sternoptychidae, with a new classification of stomiatoid families. Bulletin of the American Museum of Natural History, 153: 327-478.

Weitzman SH, Fink SV (1985) Xenurobryconin phylogeny and putative pheromone pumps in Glandulocaudine fishes. Smithsonian Contributions to Zoology, 421: 1-121.

Weitzman SH, Fink WL (1983) Relationships of the neon tetras, a group of South American freshwater fishes (Teleostei: Characidae), with comments on the phylogeny of new world characiforms. Bulletin of the Museum of Comparative Zoology 150: 339-395.

Weitzman SH, Malabarba LR (1999) Systematics of Spintherobolus (Teleostei: Characidae: Cheirodontinae) from eastern Brazil. Ichthyological Exploration of Freshwaters 10: 1-43.

Weitzman SH, Vari RP (1987) Two new species and a new genus of miniature characid fishes (Teleostei: Characiformes) from northern South America. Proceeding of the Biological Society of Washington 100: 640-652.

Weitzman SH, Vari RP (1988) Miniaturization in South American freshwater fishes: An overview and discussion. Proceeding of the Biological Society of Washington 101: 444-465.

Zanata AM, Vari RP (2005) The family Alestidae (Ostariophysi, Characiformes): A phylogenetic analysis of a trans-Atlantic clade. Zoological Journal of the Linnean Society 145: 1-144. https://doi. org/10.1111/j.1096-3642.2005.00183.x

Zarske A (2010) Der Kolibrisalmler Trochilocharax ornatus gen. et spec. nov. - ein neuer Salmler aus Peru (Teleostei: Characiformes: Characidae). Vertebrate Zoology 60: 75-98. 